\title{
Buckling of ferritic stainless steel members under combined axial
}

\section{compression and bending}

\author{
Ou Zhao ${ }^{* a}$, Leroy Gardner ${ }^{b}$, Ben Young ${ }^{c}$ \\ ${ }^{\mathrm{a}, \mathrm{b}}$ Dept. of Civil and Environmental Engineering, Imperial College London, London, UK \\ ${ }^{c}$ Dept. of Civil Engineering, The University of Hong Kong, Pokfulam Road, Hong Kong, China \\ * Corresponding author, Phone: +44 (0)20 75946058 \\ Email: ou.zhao11@imperial.ac.uk
}

\begin{abstract}
Experimental and numerical studies of ferritic stainless steel beam-columns have been carried out and are described in this paper. Two cross-section sizes were considered in the physical testing: square hollow section (SHS) $60 \times 60 \times 3$ and rectangular hollow section (RHS) $100 \times 40 \times 2$, both of grade EN 1.4003 stainless steel. The experimental programme comprised material tensile coupon tests, geometric imperfection measurements, four stub column tests, two four-point bending tests, two axially-loaded column tests and ten beam-column tests. The initial eccentricities for the beam-column tests were varied to provide a wide range of bending moment-to-axial load ratios. All the test results were then employed for the validation of finite element (FE) models, by means of which a series of parametric studies was conducted to generate further structural performance data. The obtained test and FE results were utilized to evaluate the accuracy of the capacity predictions according to the current European code, American specification and Australian/New Zealand Standard, together with other recent proposals, for the design of stainless steel beam-columns. Overall,
\end{abstract}


the Australian/New Zealand Standard was found to offer the most suitable design provisions, though further improvements remain possible.

\section{Introduction}

The physical and mechanical characteristics of ferritic stainless steels, coupled with their durability, make them an increasingly attractive choice in structural applications. Compared to the more commonly used austenitic stainless steel grades, ferritic stainless steels exhibit similar weldability and corrosion resistance but have higher strength and better machinability [1]. In addition, ferritic stainless steels have a much lower and more stable material price than austenitic stainless steels since they contain almost no nickel, which has a significant influence on the initial cost of stainless steel. Research into ferritic stainless steel structural members susceptible to global instability has been conducted previously and a brief review of the key studies is provided herein. Hyttinen [2] carried out tests on tubular specimens subjected to combined axial compression and transverse forces to investigate the buckling behaviour of ferritic stainless steel beam-columns under a trapezoidal moment distribution. Van den Berg [3] collected previous test data on ferritic stainless steel open sections and studied the flexural-torsional buckling behaviour of I-section columns and the lateraltorsional buckling behaviour of lipped channel section beams. Column tests on ferritic stainless steel lipped channel section members were performed by Lecce and Rasmussen [4], Becque and Rasmussen [5] and Rossi et al. [6] to investigate their distortional, local-overall and distortional-overall buckling behaviour, respectively. A series of column and beam tests on ferritic stainless steel slender I-sections were carried out by Becque and Rasmussen [7] and Niu and Rasmussen [8] to study the interaction of local and global buckling behaviour of structural members under compression and bending, respectively. Afshan and Gardner [9] 
conducted experimental and numerical studies on pin-ended tubular members. Comparisons between test results and the capacity predictions of EN 1993-1-4 [10], SEI/ASCE-8 [11] and AS/NZS 4673 [12] revealed that these codes generally overestimate the flexural buckling strengths of ferritic stainless steel columns, and revised buckling curves have been proposed [9]. However, to date, the structural performance of ferritic stainless steel beam-columns under combined axial load and uniform first order bending moment remains unexplored; hence this is the subject of the present paper.

An experimental programme on ferritic stainless steel tubular beam-columns was firstly carried out. The experimental pool of structural performance was added to the results of a parallel numerical investigation, in which a calibration study was initially undertaken to validate FE models against the test results, and a parametric study was then performed to generate further data over a wider range of cross-section sizes, member non-dimensional slenderness and combinations of loading. The experimental data, together with the numerical results, were used to evaluate the applicability of the current beam-column design provisions given in EN 1993-1-4 [10], SEI/ASCE-8 [11] and AS/NZS 4673 [12]. The design proposals of Greiner and Kettler [13] were also carefully assessed.

\section{Experimental investigation}

\subsection{General}

A test programme was conducted to investigate the beam-column buckling behaviour of ferritic stainless steel tubular members at the University of Hong Kong. The two employed cross-sections were SHS $60 \times 60 \times 3$ and RHS $100 \times 40 \times 2$ made of grade EN 1.4003 stainless 
steel. Overall, the experimental programme comprised material tensile coupon tests, geometric imperfection measurements, four stub column tests, two beam (four-point bending) tests, two column (flexural buckling) tests and ten beam-column tests. For each of the two studied cross-sections, the different types of test specimens were extracted from the same batch of material. The testing setup, experimental procedures and test results for each type of test are fully described in the following sections.

\subsection{Material testing}

Tensile coupon tests were firstly conducted to determine the material stress-strain response of both the flat and corner portions of the test specimens. For each cross-section, two flat coupons and one corner coupon were tested; the flat coupons were extracted from the centrelines of the faces adjacent to the welded face whilst the corner coupons were taken near the weld, as shown in Fig. 1. The coupons were machined in accordance with the dimensional requirements of the Australian Standard AS 1391 [14] and the American Standard ASTM E8M [15]. The flat coupons were $12.5 \mathrm{~mm}$ wide with a $50 \mathrm{~mm}$ gauge length while the corner coupons were $4 \mathrm{~mm}$ in width with a gauge length of $25 \mathrm{~mm}$. The tensile coupon tests were conducted using an MTS $250 \mathrm{kN}$ testing machine. Displacement control was used to drive the testing machine at the rate of $0.05 \mathrm{~mm} / \mathrm{min}$ and $0.2 \mathrm{~mm} / \mathrm{min}$ up to and beyond $0.2 \%$ proof stress, respectively. The instrumentation consisted of an extensometer mounted onto the specimens through three-point contact knife edges and two strain gauges affixed to the midlength of the coupons. The strain gauge readings were initially employed to determine the Young's modulus of the material and then used to calibrate the strain measurements from the extensometer. 
The average measured flat and corner material properties are summarized in Tables $1-2$, respectively, where $E$ is the Young's modulus, $\sigma_{0.2}$ is the $0.2 \%$ proof stress, $\sigma_{1.0}$ is the $1.0 \%$ proof stress, $\sigma_{u}$ is the ultimate tensile strength, $\varepsilon_{u}$ is the strain at the ultimate tensile stress, $\varepsilon_{f}$ is the plastic strain at fracture measured over the standard gauge length $(50 \mathrm{~mm}$ for the flat coupons and $25 \mathrm{~mm}$ for the corner coupons), and $n, n_{0.2,1.0}^{\prime}$ and $n_{0.2, u}^{\prime}$ are the strain hardening exponents used in the compound Ramberg-Osgood ( $\mathrm{R}-\mathrm{O})$ material model [16-20]. The measured tensile stress-strain curves are depicted in Figs 2 and 3 for the flat and corner coupons, respectively.

\subsection{Initial geometric imperfection measurements}

Prior to the member tests, geometric imperfections of the specimens were measured. For initial local geometric imperfections, measurements were not conducted specifically for each test specimen but carried out over a representative $500 \mathrm{~mm}$ length of each section size, following the procedures and test setup used by Schafer and Peköz [21], in which a Linear Voltage Differential Transducer (LVDT) with an accuracy of $0.001 \mathrm{~mm}$ was affixed to the head of a milling machine with specimens lying on the moving machine base. The maximum imperfection amplitude of each face was defined as the maximum deviation from a linear trend line fitted to the data set, while the maximum imperfection amplitude of the specimen $\omega_{0}$ was taken as the largest value of the measured maximum deviations from all the four faces. Fig. 4 depicts the measured local geometric imperfection distributions for the four faces of the SHS $60 \times 60 \times 3$. Initial global geometric imperfections $\omega_{g}$ of the column and beam-column specimens in the direction of buckling were measured using a theodolite, based on the measurements taken at mid-height and near both ends of the specimens. 


\subsection{Stub column tests}

For each cross-section, two repeated stub column tests were performed to obtain the crosssectional load-carrying capacity under pure compression. The nominal length for each specimen conformed to the guidelines of Ziemian [22]. The geometric dimensions and imperfection amplitudes of the stub columns were carefully measured and are reported in Table 3, where $L$ is the member length, $B$ is the outer cross-section width, $H$ is the outer cross-section depth, $t$ is the material thickness, $r_{i}$ is the internal corner radius, and $\omega_{0}$ is the measured maximum local geometric imperfection. The stub columns were compressed in an INSTRON $5000 \mathrm{kN}$ hydraulic testing machine, at a constant speed of $0.2 \mathrm{~mm} / \mathrm{min}$. The test setup consisted of three LVDTs to determine the end shortening and three strain gauges, affixed to the specimen at mid-height, to measure the axial strains, as depicted in Fig. 5(a). A special device, as shown in Fig. 5(b), was clamped to both ends of the specimens in order to eliminate any possible local failure at the ends due to any out-of-flatness of the end surfaces. The true end-shortening values were obtained by eliminating the elastic deformation of the end platens of the testing machine from the end-shortening measurements on the basis of the strain gauge readings [23]. This was achieved by assuming that the end platen deformation was proportional to the applied load and shifting the load-end shortening curves derived from the LVDTs such that the initial slope matched that obtained from the strain gauges. Fig. 6 depicts the modified true load-end shortening curves, while Table 3 summarizes the key test results, including the ultimate load $N_{u}$ and the corresponding end shortening $\delta_{u}$ at the ultimate load. All the stub columns failed by inelastic local buckling with the typical deformed specimens shown in Fig. 7. 


\subsection{Four-point bending tests}

Four-point bending tests were conducted to investigate the flexural performance and rotation capacity of ferritic stainless steel sections under constant bending moment. With the absence of an axial force, these beams represent a special case of the more general beam-column response, and an 'end point' on the axial load-bending moment interaction curve. For the RHS $100 \times 40 \times 2$, the bending test was conducted about the minor axis. The measured geometric properties of the tested beams are reported in Table 4. Both the specimens had a total length of $1100 \mathrm{~mm}$ and a length between the loading points of $400 \mathrm{~mm}$. A half-cylinder steel roller and a rounded steel roller, placed $50 \mathrm{~mm}$ inward from the two ends of the beams, were employed to provide simple supports to the specimens. The beams therefore had a span of $1000 \mathrm{~mm}$. The test setup is shown in Fig. 8, where web stiffening plates were clamped at the two loading points and wooden blocks were also inserted into the tubes at these locations in order to avoid any possible web crippling. Three LVDTs were placed at mid-span and at the two loading points to measure the respective vertical deflections, which were then used to approximate the curvature [24]. Displacement control was used to drive the hydraulic actuator at a constant speed of $1 \mathrm{~mm} / \mathrm{min}$ for all tests. Table 4 reports the key experimental results from the beam tests, including the experimental ultimate moment $M_{u}$ and the curvature at the ultimate moment $\kappa_{u}$. The experimental moment-curvature curves are shown in Fig. 9, while a typical four-point bending failure mode is displayed in Fig. 10.

\subsection{Beam-column tests}

For each cross-section, six beam-column tests under uniaxial bending plus compression were performed to investigate the buckling behaviour of ferritic stainless steel tubular section 
beam-column members. The nominal initial loading eccentricities were varied to provide a range of proportions of moment-to-axial load. For the special case when the nominal initial loading eccentricity is equal to zero, the beam-column tests are equivalent to a column test, and represent the second 'end point' on the axial load-bending moment interaction curve. Measurements of the geometric properties and initial local and global imperfection amplitudes of the specimens were conducted prior to $25.4 \mathrm{~mm}$ end plates being welded to the member ends, and are reported in Table 5, in which $L_{e}$ is the effective member length (measured between the pinned ends), and $\bar{\lambda}=\sqrt{A_{e f f} \sigma_{0.2} / N_{c r}}$ is the non-dimensional column slenderness, where $A_{\text {eff }}$ is the effective cross-section area calculated according to the effective width method in EN 1993-1-4 [10], and $N_{c r}=\pi^{2} E I / L_{e}{ }^{2}$ is the Euler buckling load about the considered buckling axis. The beam-column tests were conducted using an AVERY $1000 \mathrm{kN}$ hydraulic testing machine with pin-ended bearings at both ends. Each pin-ended bearing was made up of a wedge plate containing a knife-edge wedge, and a pit plate with a V-shaped groove, as illustrated in Figs 11(a) and 11(b), showing a photograph and schematic diagram of the beam-column test setup. The specimens were bolted to the wedge plates, which had slotted holes to allow adjustment of the relative position between the centrelines of the specimen and the knife-edge. The specimens, together with the wedge plates, were then positioned in the testing machine between the two pit plates. To eliminate any possible gap between the knife-edges and the $\mathrm{V}$-grooved pit plates, the bottom pit plate, seated on a special bearing, was initially free to rotate in any direction and a small alignment load of 2 $\mathrm{kN}$ was then applied. At this point, the bottom pit plate was restrained against rotation and twist deformations by tightening the vertical and horizontal bolts. The test setup, as depicted in Figs 11(a) and 11(b), consisted of three LVDTs located at one end of the test members to determine the axial end shortening and end rotation, one additional LVDT placed at the midheight of the specimens to measure the lateral deflection, and four strain gauges affixed to the 
extreme tensile and compressive fibres of the sections at mid-height to obtain the longitudinal strains. The strains were made up of two components: (i) strains due to the applied compressive load, and (ii) strains due to the corresponding bending moment, which were employed for the determination of the actual initial loading eccentricities, following the procedures in [25-28]. All the beam-column tests were performed under displacementcontrol at a constant speed of $0.2 \mathrm{~mm} / \mathrm{min}$. Finally, a data acquisition system was used to record the applied load, LVDT readings, and strain gauge values at regular intervals during the tests. Table 6 reports the key experimental results, including the initial measured (nominal) loading eccentricity $e_{m}$, the initial calculated loading eccentricity $e_{0}$, determined on the basis of the strain gauge readings, the ultimate load $N_{u}$, the mid-height lateral deflection at the ultimate load $\delta_{u}$, the end rotation at failure $\phi_{u}$, and the first-order elastic, second order elastic and second order inelastic bending moments at the ultimate load $\left(M_{1 s t, e l, u}, M_{2 n d, e l, u}\right.$, and $\left.M_{2 n d, \text { inel, }}\right)$, which are determined from Eqs (1)-(3) [29], respectively,

$$
\begin{gathered}
M_{1 s t, e l, u}=N_{u}\left(e_{0}+\omega_{g}\right) \\
M_{2 n d, e l, u}=M_{1 s t, e l, u} /\left(1-N_{u} / N_{c r}\right) \\
M_{2 n d, i n e l, u}=N_{u}\left(e_{0}+\omega_{g}+\delta_{u}\right)
\end{gathered}
$$

The full experimental load-mid-height lateral deflection curves are depicted in Figs 12(a) and 12(b) for the SHS $60 \times 60 \times 3$ and RHS $100 \times 40 \times 2$ specimens, respectively. The obtained failure modes involved in-plane bending and flexural buckling for both cross-section sizes, accompanied also by local buckling in the case of the more slender RHS $100 \times 40 \times 2$ specimens; typical failure modes are shown in Figs 13 and 14. 


\section{Numerical modelling}

\subsection{Basic modelling assumptions}

In parallel with the experimental study, a numerical modelling programme, using the nonlinear finite element analysis package ABAQUS [30], was performed. Finite element models were initially validated against the test results and subsequently used to conduct parametric studies to generate additional structural performance data over a wider range of cross-section and member non-dimensional slenderness, and combinations of loading.

Having been successfully used in previous studies [31-39] concerning the modelling of thinwalled structures, the four-noded doubly curved shell element with reduced integration, S4R [30], was employed in the present numerical investigation for the modelling of tubular beamcolumns. A mesh sensitivity study was firstly conducted based on elastic eigenvalue buckling analyses, in order to choose a mesh size that would achieve accurate numerical results while maintaining computational efficiency. An element size equal to the cross-section thickness in the flat portions of the modelled cross-sections, with a finer mesh of 4 elements in the corner regions, was found to be suitable. The measured stress-strain curves, represented by the compound two-stage Ramberg-Osgood material model $[18,20]$, were converted into the format of true stress and log plastic strain by means of Eqs (4) and (5) and then inputted into ABAQUS, where $\sigma_{\text {true }}$ is the true stress, $\varepsilon_{l n}^{p l}$ is the $\log$ plastic strain, $\sigma_{\text {nom }}$ is the engineering stress and $\varepsilon_{n o m}$ is the engineering strain. The measured corner material properties were not assigned only to the corners, but also to the adjacent flat portions beyond the corners by a distance equal to two times the material thickness, in accordance with the previous finding [40-43] that both of the aforementioned regions approximately experience the same degree of 
strength enhancement during the cold-rolling process and thus exhibit similar stress-strain characteristics.

$$
\begin{aligned}
& \sigma_{\text {true }}=\sigma_{\text {nот }}\left(1+\varepsilon_{\text {nот }}\right) \\
& \varepsilon_{\text {ln }}^{p l}=\ln \left(1+\varepsilon_{\text {nom }}\right)-\frac{\sigma_{\text {true }}}{E}
\end{aligned}
$$

Since the experimental beam-column failure modes were symmetric with respect to the midheight plane and the plane perpendicular to the buckling axis, only half of the cross-section and effective member length were modelled. All degrees of freedom of the nodes of the loaded end section were coupled to an eccentric reference point; the eccentricity was equal to the value adopted in the test, and the reference point only allowed longitudinal translation and rotation about the axis of buckling, in order to simulate pin-ended boundary conditions. Symmetry was also exploited in the numerical simulations of beam specimens by modelling only half of the cross-section and member length. Similar end section boundary conditions as those for the beam-column FE models were applied to the beam FE models, with the only difference being that the reference point was located at the mid-point of the bottom flange in order to replicate the simply-supported conditions in the beam tests. In addition, the crosssection of the beam model under the loading point was set as a rigid body, which only allowed rotation about the loading point and vertical deflection.

The lowest local and global buckling mode shapes, determined by means of an elastic eigenvalue buckling analysis, were assumed for the respective imperfection patterns along the member length and incorporated into the beam-column FE models. Sensitivity studies were performed by considering two local and three global imperfection amplitudes. The two considered values for local imperfection were the measured amplitude $\omega_{0}$ and the 
imperfection amplitude $\omega_{D \& W}$ predicted by the modified Dawson and Walker (D\&W) model [40,44], as given by Eq. (6), in which $\sigma_{c r, \min }$ is the minimum elastic buckling stress of all the plate elements making up the cross-section. Three different imperfection amplitudes were utilized to factor the lowest global buckling mode shape in the models, including the measured global imperfection amplitude $\omega_{g}$, and two fractions of the effective member length $\left(L_{e} / 1000\right.$ and $\left.L_{e} / 1500\right)$. For beam FE models, only the lowest local buckling mode shape was used to perturb the geometry with three imperfection levels $\left(\omega_{0}, \mathrm{t} / 100\right.$ and $\left.\omega_{D \& W}\right)$, which are reported in Table 7 , where the values of $\omega_{D \& W}$ are equal to those employed in the beamcolumn FE models, since the most slender plate elements in both the tested beams and beamcolumns are the compressive flanges. Upon incorporation of the initial geometric imperfections into the models, geometrically and materially nonlinear analyses, based on the static modified Riks method [30], were carried out to trace the full load-deformation histories of the FE models.

$$
\omega_{D \& W}=0.023\left(\frac{\sigma_{0.2}}{\sigma_{c r, \text { min }}}\right) t
$$

\subsection{Validation of numerical models}

The accuracy of the beam-column FE models with the various considered combinations of local and global imperfection levels was evaluated, as reported in Table 8 , by means of the ratio of numerical to experimental ultimate loads, showing that good agreement between the test and FE failure loads is generally achieved for all six combinations of local and global imperfection amplitudes. It may also be observed that incorporation of the local imperfection amplitude predicted by the modified Dawson and Walker model and the global imperfection amplitude of $L_{e} / 1000$ results in the most accurate and consistent failure load predictions, with 
the mean FE to test failure load ratio equal to 1.01 and a corresponding coefficient of variation $(\mathrm{COV})$ equal to 0.035 . Good agreement between the test and FE failure loads for the beams is also obtained for all the three considered local imperfection values, as reported in Table 9. Comparisons between the experimental and numerical load-deformation curves for typical tested beams and beam-columns are depicted in Figs 15 and 16, where the numerical load-deformation histories may be seen to replicate accurately those from the tests. The failure modes from the numerical models are also in excellent agreement with the corresponding experimental failure modes, as shown in Figs 10, 13 and 14. Overall, it may be concluded that the finite element models are capable of predicting the key test results, replicating the full experimental load-deformation histories and capturing the observed failure modes, and thus are suitable for performing parametric studies.

\subsection{Parametric studies}

Having validated the FE models, parametric studies were conducted to generate further beam-column data over a wider range of cross-section sizes, member non-dimensional slenderness, and combinations of loading. In the parametric studies, the measured flat and corner material properties of the SHS $60 \times 60 \times 3$ were used. The initial local imperfection amplitudes were predicted using the modified Dawson and Walker model, while the global imperfection amplitudes were taken as $1 / 1000$ of the effective member length. The modelled specimens covered all four classes of cross-section according to the slenderness limits in EN 1993-1-4 [10], with the ratio of $C / t \varepsilon$ ranging from 8.7 to 103.3 , where $C$ is the flat element width and $\varepsilon=\sqrt{\left(235 / \sigma_{0.2}\right)(E / 210000)}$. The bucking lengths of the beam-column FE

models were varied to cover a wide spectrum of member slenderness $\bar{\lambda}$ between 0.41 and 3.26, and the initial loading eccentricities ranged from $0 \mathrm{~mm}$ to $500 \mathrm{~mm}$, enabling a broad 
range of loading combinations (i.e. ratios of axial load to bending moment) to be considered. The length of each beam model was set to be equal to twelve times the width of its widest plate element. In total, 110 parametric results were generated for specimens with Class 1 or 2 cross-sections, 120 for Class 3 cross-sections and 110 for Class 4 cross-sections.

\section{Discussion and assessment of current design methods}

\subsection{General}

In this section, four methods for the design of ferritic stainless steel tubular section beamcolumns under uniaxial bending plus compression, including three codified methods: EN 1993-1-4 [10], SEI/ASCE-8 [11] and AS/NZS 4673 [12] and a proposed approach by Greiner and Kettler [13], are fully described and examined. The accuracy of each method is evaluated by means of the ratio of test (or FE) capacity to predicted capacity, calculated in terms of the axial load, $N_{u} / N_{u, p r e d}$, in Tables 10-12 for beam-columns with Class 1 or 2, Class 3 and Class 4 cross-sections, respectively, where $N_{u}$ is the ultimate test (or FE) axial load corresponding to the distance on the $\mathrm{N}-\mathrm{M}$ interaction curve from the origin to the test (or FE) data point (see Fig. 17), while $N_{u, \text { pred }}$ is the predicted axial load corresponding to the distance from the origin to the intersection with the design interaction curve, assuming proportional loading. A value of $N_{u} / N_{u \text {,pred }}$ greater than unity indicates that the test (or FE) data point lies outside the interaction curve and is safely predicted. Note that all comparisons have been made based on the measured material and geometric properties and on the unfactored design strengths. 


\subsection{European code EN 1993-1-4 (EC3)}

The EN 1993-1-4 [10] provisions for stainless steel beam-column design mirror those for carbon steel, but with modified interaction buckling factors to consider the nonlinear material response and gradual yielding of stainless steel. The design formula for tubular section beamcolumns under uniaxial bending plus compression is shown in Eq. (7), where $N_{E d}$ is the design axial load, $M_{E d}=N_{E d} e_{0}$ is the design maximum first order bending moment about the considered buckling axis, $N_{b, R d}$ is the column buckling strength, calculated according to Clause 5.4.2 of EN 1993-1-4 for uniform members in compression, $e_{N}$ is the shift in the neutral axis when the cross-section is subjected to uniform compression, which is equal to zero for SHS and RHS, $W_{p l}$ is the plastic section modulus about the buckling axis, $\beta_{W}$ is a factor that is equal to unity for Class 1 or 2 sections, the ratio of elastic to plastic moduli for Class 3 sections and the ratio of effective to plastic moduli for Class 4 cross-sections, and $k$ is the buckling interaction factor, as defined by Eq. (8), where $\bar{\lambda}$ is the non-dimensional column slenderness about the considered buckling axis.

$$
\begin{gathered}
\frac{N_{E d}}{N_{b, R d}}+k\left(\frac{M_{E d}+N_{E d} e_{N}}{\beta_{W} W_{p l} \sigma_{0.2}}\right) \leq 1 \\
1.2 \leq k=1+2(\bar{\lambda}-0.5) \frac{N_{E d}}{N_{b, R d}} \leq 1.2+2 \frac{N_{E d}}{N_{b, R d}}
\end{gathered}
$$

The applicability of the EN 1993-1-4 [10] interaction buckling formula to ferritic stainless steel tubular beam-columns under uniaxial bending plus compression is assessed by comparing the experimental and numerical results with the EC3 predicted capacities. As reported in Tables 10-12, the mean ratio of beam-column test (or FE) to EC3 predicted capacities $N_{u} / N_{u, E C 3}$ for Class 1 or 2 cross-sections is equal to 1.07 with a coefficient of the 
variation $(\mathrm{COV})$ equal to 0.06 , revealing acceptable accuracy, while the mean values of $N_{u} / N_{u, E C 3}$ ratio are equal respectively to 1.17 and 1.20 for Class 3 and Class 4 cross-sections with COVs of 0.09 and 0.08 , indicating unduly conservative and scattered strength predictions; this can also be seen in Fig. 18, where the test and FE capacities are plotted against the EC3 predicted capacities. The conservatism of EN 1993-1-4 mainly results from inaccurate predictions of the end points of the interaction curves, particularly the bending end points (i.e. cross-section moment capacity under pure bending) which suffer from being determined without considering the influence of strain hardening and element interaction, and from inaccurate interaction factors, which generally underestimate the plasticity effects in the interaction.

\subsection{American Specification SEI/ASCE-8}

The stainless steel beam-column formulae in the American specification SEI/ASCE-8 [11] were derived on the basis of second-order elastic theory, as given by Eq. (9) for either principal axis, where $N_{n}$ is the column buckling strength, calculated in accordance with Section 3.4 of SEI/ASCE-8 [11], which utilises the tangent modulus approach to allow for the nonlinear material response of stainless steel in the design of column members, $M_{n}$ is the codified bending resistance calculated using the inelastic reserve capacity provisions of Clause 3.3.1.1, $C_{m}$ is the equivalent moment factor, which is equal to unity for a beamcolumn with constant first order bending moment along the member length, and $\alpha_{m}$ is the magnification factor equal to $\left(1-N_{E d} / N_{c r}\right)$.

$$
\frac{N_{E d}}{N_{n}}+\frac{C_{m} M_{E d}}{M_{n} \alpha_{m}} \leq 1
$$


As indicated by Afshan and Gardner [9] and Zhao et al. [28], SEI/ASCE-8 [11] generally overpredicts the actual strength of ferritic stainless steel columns, while the inelastic reserve capacity provisions underestimate the cross-section bending resistance. Thus, the SEI/ASCE stainless steel beam-column design rules generally result in unsafe member capacity predictions when compression effects dominate, but lead to unduly conservative resistance predictions for beam-columns with large bending moments. This is demonstrated in Fig. 19, where the test (or FE) to ASCE predicted failure load ratio $N_{u} / N_{u, A S C E}$ is plotted against the angle parameter $\theta$, which is defined by Eq. (10) and illustrated in Fig. 20, together with a linear trend line fitted to the data. Note that $\theta=0^{\circ}$ corresponds to pure bending while $\theta=90^{\circ}$ represents pure compression. The above issue is also shown in Fig. 21, where the numerical results for a beam-column with a constant cross-section size and member slenderness (SHS $100 \times 100 \times 10$ with a length of $2500 \mathrm{~mm}$ ), but varying ratios of axial load to bending moment are presented.

$$
\theta=\tan ^{-1}\left[\left(N_{E d} / N_{n}\right) /\left(M_{E d} / M_{n}\right)\right]
$$

A numerical evaluation of the American specification is reported in Tables 10-12. Although the mean values of the $N_{u} / N_{u, A S C E}$ ratio $(0.98,0.98$ and 1.02 for Class 1 or 2, Class 3 and Class 4 cross-sections, respectively) are generally close to unity, they result in unsafe strength predictions for a significant portion of the considered 354 test and FE cases, as can be seen from Fig. 19.

\subsection{Australian/New Zealand standard AS/NZS 4673}

The Australian/New Zealand standard AS/NZS 4673 [12] uses the same beam-column design formula as the American specification but with differences in the determination of column 
buckling strength $N_{a}$ and bending moment capacity $M_{a}$. For the calculation of column buckling strength, an alternative explicit method [45] is given in AS/NZS 4673 [12], which is based on the Perry-Robertson buckling formulation with a series of imperfection parameters for different stainless steel grades to account for the differing levels of nonlinearity. AS/NZS 4673 [12] uses the same inelastic reserve capacity provisions to determine bending moment capacity, but allows use of the full plastic moment capacity provided that the flat width-tothickness ratio is less than a specified slenderness limit. Thus, the AS/NZS 4673 [12] beamcolumn design formula maintains the general format of Eq. (9), but with $N_{a}$ and $M_{a}$ replacing $N_{n}$ and $M_{n}$, as given by Eq. (11). The applicability of the AS/NZS 4673 design rules to ferritic stainless steel tubular beam-columns under uniaxial bending plus compression is evaluated by comparing the test (or FE) capacity to the predicted capacity. Tables $10-12$ reveal that the AS/NZS standard yields generally safe strength predictions but with slight conservatism, as indicated in Fig. 22. The mean $N_{u} / N_{u, A S / N Z S}$ ratios for Class 1 (or 2), Class 3 and Class 4 crosssections are equal to $1.06,1.05$ and 1.09 , respectively, with the corresponding COVs equal to $0.04,0.03$ and 0.04 .

$$
\frac{N_{E d}}{N_{a}}+\frac{C_{m} M_{E d}}{M_{a} \alpha_{m}} \leq 1
$$

\subsection{Greiner and Kettler's Method}

Greiner and Kettler [13] proposed a new set of interaction buckling factors for stainless steel tubular beam-columns, based on numerical simulations, and the traditional derivation procedures and general format of the Eurocode beam-column formulae for carbon steel. Note that the proposed interaction buckling factors only applied to compact Class 1 and 2 crosssections, while investigations into beam-columns of Class 3 and 4 sections have yet to be 
presented. The beam-column design formula and the corresponding proposed interaction factor are given by Eqs (12) and (13), respectively.

$$
\begin{gathered}
\frac{N_{E d}}{N_{b, R d}}+k_{G \& K} \frac{M_{E d}}{W_{p l} \sigma_{0.2}} \leq 1 \\
k_{G \& K}=0.9+3.5\left(\frac{N_{E d}}{N_{b, R d}}\right)^{1.8}(\bar{\lambda}-0.5) \leq 0.9+1.75\left(\frac{N_{E d}}{N_{b, R d}}\right)^{1.8}
\end{gathered}
$$

The test and FE results are compared with the strength predictions of Greiner and Kettler in Table 10. The comparisons show that Greiner and Kettler's method results in an accurate mean ratio of test (or FE) to predicted capacities $\left(N_{u} / N_{u, G \& K}=1.00\right)$, with a COV of 0.06 . However, as with the SEI/ASCE provisions, many of the predictions are on the unsafe side, as can be seen from Fig. 23, where the test and FE strengths are plotted against the predicted strengths.

\subsection{Summary}

Overall, the European code EN 1993-1-4 [10] leads to the most conservative and scattered strength predictions among the four methods for the design of ferritic stainless steel tubular section beam-columns, mainly owing to the inaccurate end points and interaction factors. The American specification SEI/ASCE-8 [11] and Greiner and Kettler's method [13] generally result in unsafe capacity predictions. The Australian/New Zealand standard AS/NZS 4673 [12] yields safe predictions but with slight conservatism. Figs 24 and 25 depict comparisons of the beam-column test results with the design interaction curves obtained from the aforementioned four methods for the SHS $60 \times 60 \times 3$ and RHS $100 \times 40 \times 2$ specimens, respectively. Note that the test results and design curves in Figs 24 and 25 are normalised by the yield load and plastic moment capacity for comparison purposes. Overall, the presented 
results have highlighted some shortcomings in existing design rules for stainless steel tubular beam-columns; the development of improved provisions is underway as part of a wider study.

\section{Conclusions}

A comprehensive experimental and numerical modelling programme has been performed to investigate the structural performance of ferritic stainless steel tubular beam-columns under uniaxial bending plus compression. A series of tests, including two column tests, two fourpoint bending tests and ten beam-column tests, were firstly carried out. The experimental results were then used in the numerical modelling programme for the validation of FE models. Parametric studies were then conducted to generate further structural performance data over a wide range of cross-section sizes, member non-dimensional slenderness and combinations of loading. The obtained 14 test and $340 \mathrm{FE}$ results were employed to evaluate the applicability of current beam-column design methods, including the European code EN 1993-1-4 (2006) [10], American specification SEI/ASCE-8 (2002) [11], Australia and New Zealand standard AS/NZS 4673 (2001) [12] and Greiner and Kettler's method [13]. Generally, the European code leads to the most conservative and scattered strength predictions among the four methods. The American specification and the proposal by Greiner and Kettler overpredict most of the test and FE beam-column strengths, while the Australian/New Zealand standard generally results in safe though slightly conservative predictions. It is therefore concluded that there still exists room for improvement in the design of ferritic stainless steel tubular beam-columns, and further research is underway. 


\section{Acknowledgements}

The authors are grateful to Joint $\mathrm{PhD}$ Scholarship from Imperial College London and the University of Hong Kong for its financial support.

\section{References}

[1] Cashell KA, Baddoo NR. Ferritic stainless steels in structural applications. Thin-Walled Structures, 2014;83:169-81.

[2] Hyttinen V. Design of cold-formed stainless steel SHS beam-columns. Report 41. University of Oulu, Oulu, Finland; 1994.

[3] Van Den Berg GJ. The effect of non-linear stress-strain behaviour of stainless steels on member capacity. Journal of Constructional Steel Research, 2000;135(1):135-60.

[4] Lecce M, Rasmussen KJR. Distortional buckling of cold-formed stainless steel sections: experimental investigation. Journal of Structural Engineering (ASCE), 2006;132(4):497-504.

[5] Becque J, Rasmussen KJR. Experimental investigation of local-overall interaction buckling of stainless steel lipped channel columns. Journal of Constructional Steel Research, 2009;65(8):1677-84.

[6] Rossi B, Jaspart JP, Rasmussen KJR. Combined distortional and overall flexural-torsional buckling of cold-formed stainless steel sections: Experimental investigations. Journal of Structural Engineering (ASCE), 2010;136(4):361-9. 
[7] Becque J, Rasmussen KJR. Experimental investigation of the interaction of local and overall buckling of stainless steel I-columns. Journal of Structural Engineering (ASCE), $2009 ; 135(11): 1340-8$.

[8] Niu S, Rasmussen KJR, Fan F. Local-Global Interaction Buckling of Stainless Steel IBeams. I: Experimental Investigation. Journal of Structural Engineering (ASCE), 2015;141(8), 04014194.

[9] Afshan S, Gardner L. Experimental study of cold-formed ferritic stainless steel hollow sections. Journal of Structural Engineering (ASCE), 2013;139(5):717-28.

[10] EN 1993-1-4. Eurocode 3: Design of steel structures - Part 1.4: General rules Supplementary rules for stainless steels. Brussels: European Committee for Standardization (CEN); 2006.

[11] SEI/ASCE 8-02. Specification for the design of cold-formed stainless steel structural members. Reston: American Society of Civil Engineers (ASCE); 2002.

[12] AS/NZS 4673. Cold-formed stainless steel structures. Sydney: AS/NZS 4673:2001; 2001.

[13] Greiner R, Kettler M. Interaction of bending and axial compression of stainless steel members. Journal of Constructional Steel Research, 2008;64(11):1217-24.

[14] AS. Metallic materials - tensile testing at ambient temperature. Sydney: AS 1391-2007; 2007. 
[15] ASTM E.8M. Standard test methods for tension testing for metallic materials. West Conshohocken (USA): E 8M-97; 1997.

[16] Ramberg W, Osgood WR. Description of stress-strain curves by three parameters. Technical note No 902, Washington DC: National advisory committee for aeronautics; 1943.

[17] Hill HN. Determination of stress-strain relations from offset yield strength values. Technical note No 927, Washington DC: National advisory committee for aeronautics; 1944.

[18] Mirambell E, Real E. On the calculation of deflections in structural stainless steel beams: An experimental and numerical investigation. Journal of Constructional Steel Research, 2000;54(1):109-33.

[19] Ashraf M, Gardner L, Nethercot DA. Compression strength of stainless steel crosssections. Journal of Constructional Steel Research, 2006;62(1-2):105-15.

[20] Gardner L, Ashraf M. Structural design for non-linear metallic materials. Engineering Structures, 2006;28(6):926-34.

[21] Schafer BW, Peköz T. Computational modelling of cold-formed steel: Characterizing geometric imperfections and residual stresses. Journal of Constructional Steel Research, 1998;47(3):193-210.

[22] Ziemian RD. Guide to Stability Design Criteria for Metal Structures, 6th Ed. John Wiley \& Sons, Inc., New York (USA); 2010.

[23] Centre for Advanced Structural Engineering. Compression tests of stainless steel tubular columns. Investigation report S770. University of Sydney; 1990. 
[24] Chan TM, Gardner L. Bending strength of hot-rolled elliptical hollow sections. Journal of Constructional Steel Research, 2008;64(9):971-86.

[25] Huang Y, Young B. Experimental investigation of cold-formed lean duplex stainless steel beam-columns. Thin-Walled Structures, 2014;76:105-17.

[26] Lui WM, Ashraf M, Young B. Tests of cold-formed duplex stainless steel SHS beamcolumns. Engineering Structures, 2014;74:111-21.

[27] Zhao O, Rossi B, Gardner L, Young, B. Behaviour of structural stainless steel crosssections under combined loading - Part I: Experimental study. Engineering Structures, $2015 ; 89: 236-46$

[28] Zhao O, Rossi B, Gardner L, Young B. Experimental and numerical studies of ferritic stainless steel tubular cross-sections under combined compression and bending. Journal of Structural Engineering (ASCE), 2015; 04015110.

[29] Law KH, Gardner L. Buckling of elliptical hollow section members under combined compression and uniaxial bending. Journal of Constructional Steel Research, 2013;86:1-16.

[30] Hibbitt, Karlsson \& Sorensen, Inc. ABAQUS. ABAQUS/Standard user's manual volumes I-III and ABAQUS CAE manual. Version 6.12. Pawtucket (USA); 2012.

[31] Becque J, Lecce M, Rasmussen KJR. The direct strength method for stainless steel compression members. Journal of Constructional Steel Research, 2008;64(11):1231-8.

[32] Theofanous M, Chan TM, Gardner L. Structural response of stainless steel oval hollow section compression members. Engineering Structures, 2009;31(4):922-34. 
[33] Theofanous M, Gardner L. Testing and numerical modelling of lean duplex stainless steel hollow section columns. Engineering Structures, 2009;31(12):3047-58.

[34] Theofanous M, Chan TM, Gardner L. Flexural behaviour of stainless steel oval hollow sections. Thin-Walled Structures, 2009;47(6):776-87.

[35] Theofanous M, Gardner L. Experimental and numerical studies of lean duplex stainless steel beams. Journal of Constructional Steel Research, 2010;66(6):816-25.

[36] Huang Y, Young B. Experimental and numerical investigation of cold-formed lean duplex stainless steel flexural members. Thin-Walled Structures, 2013;73(19):216-28.

[37] Hassanein MF, Silvestre N. Flexural behaviour of lean duplex stainless steel girders with slender unstiffened webs. Journal of Constructional Steel Research, 2013;85:12-23.

[38] Huang Y, Young B. Design of cold-formed lean duplex stainless steel members in compression and bending. Journal of Structural Engineering (ASCE), 10.1061/(ASCE)ST. 1943-541X.0001091, 04014138.

[39] Zhao O, Rossi B, Gardner L, Young B. Behaviour of structural stainless steel crosssections under combined loading - Part II: Numerical modelling and design approach. Engineering Structures, 2015;89:247-59.

[40] Gardner L, Nethercot DA. Numerical modeling of stainless steel structural components A consistent approach. Journal of Structural Engineering (ASCE), 2004;130(10):1586-601.

[41] Ashraf M, Gardner L, Nethercot DA. Finite element modelling of structural stainless steel cross-sections. Thin-Walled Structures, 2006;44(10):1048-62. 
[42] Cruise RB, Gardner L. Strength enhancements induced during cold forming of stainless steel sections. Journal of Constructional Steel Research, 2008;64(11):1310-6.

[43] Afshan S, Rossi B, Gardner L. Strength enhancements in cold-formed structural sections - Part I: Material testing, Journal of Constructional Steel Research, 2013;83(16):177-88.

[44] Dawson RG, Walker AC. Post-buckling of geometrically imperfect plates. Journal of the Structural Division (ASCE), 1972;98(1):75-94.

[45] Rasmussen KJR, Rondal J. Strength curves for metal columns. Journal of Structural Engineering (ASCE), 1997;123(6):721-8. 


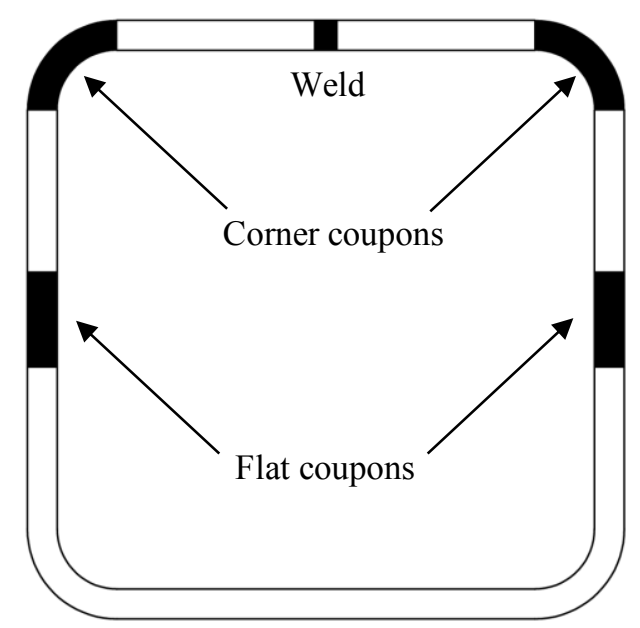

Fig. 1. Locations of coupons in the cross-section.

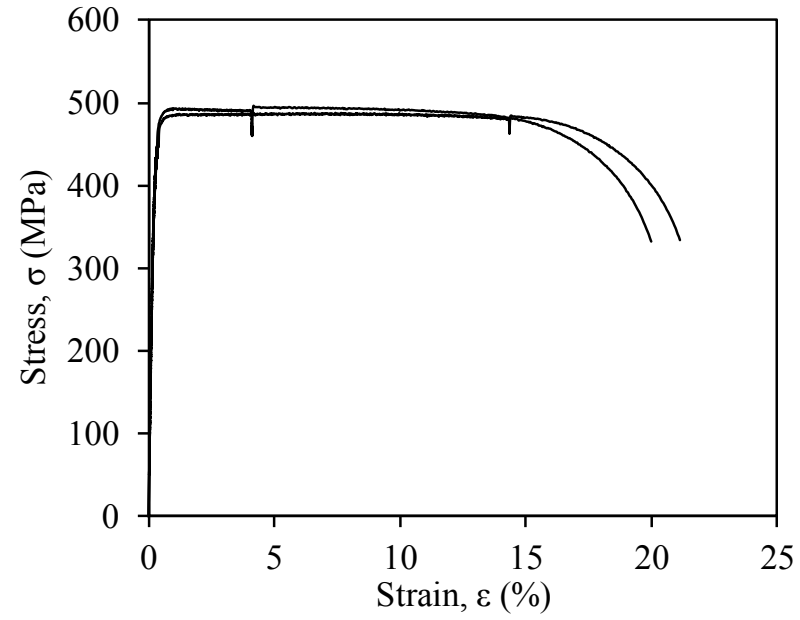

(a) SHS $60 \times 60 \times 3$.

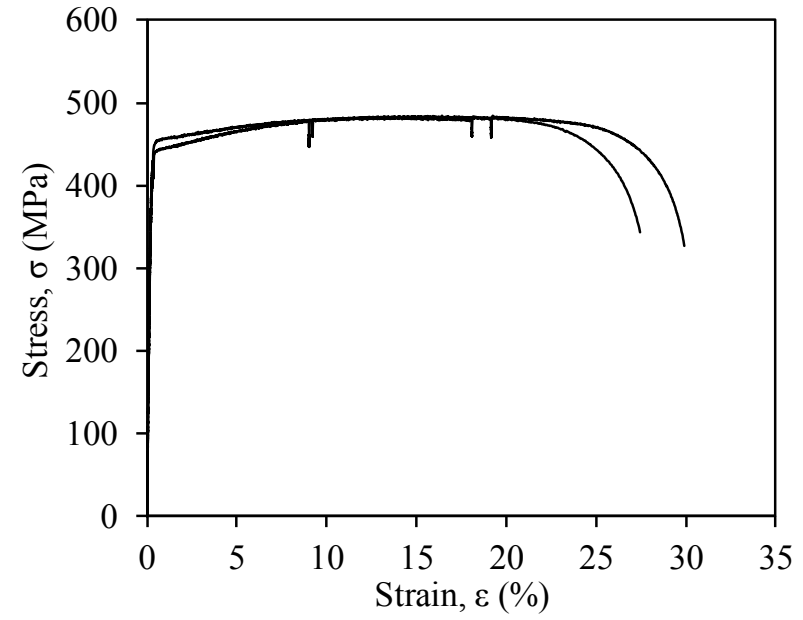

(b) RHS $100 \times 40 \times 2$.

Fig. 2. Material stress-strain curves from flat coupon tests.

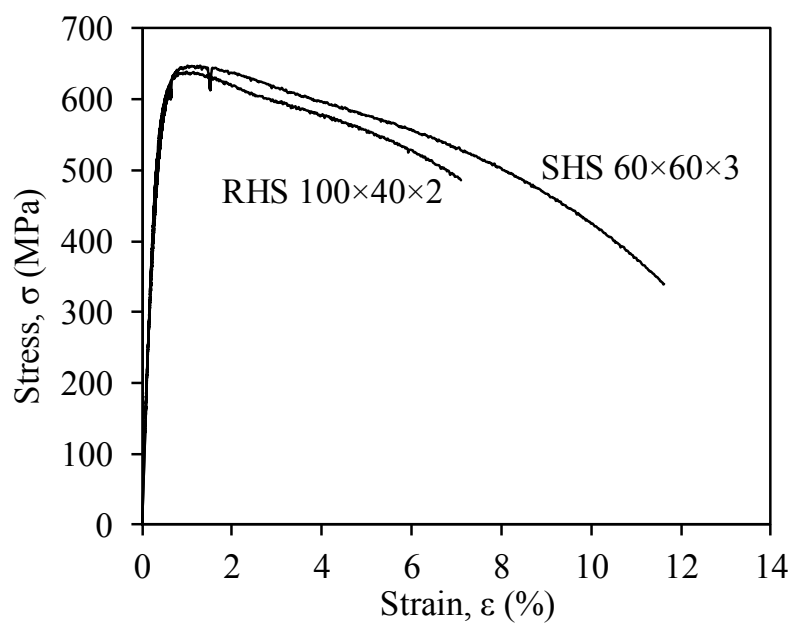

Fig. 3. Material stress-strain curves from corner coupon tests. 


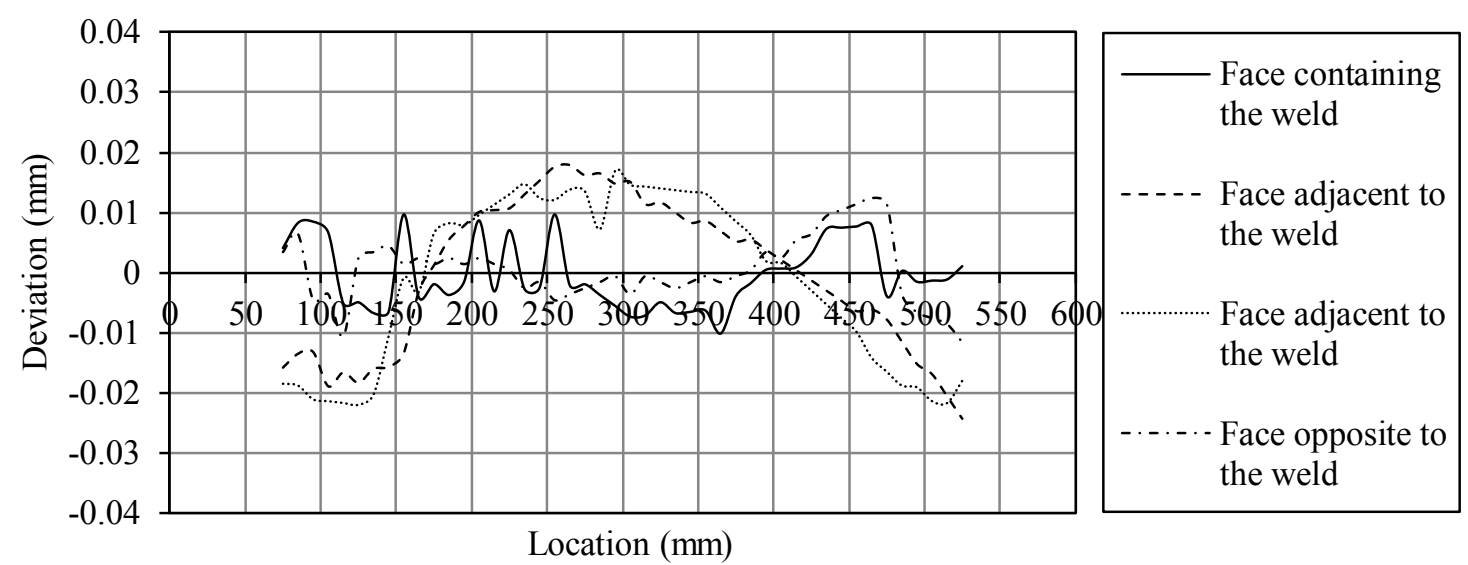

Fig. 4. Measured local geometric imperfection distributions for the SHS $60 \times 60 \times 3$ specimen.
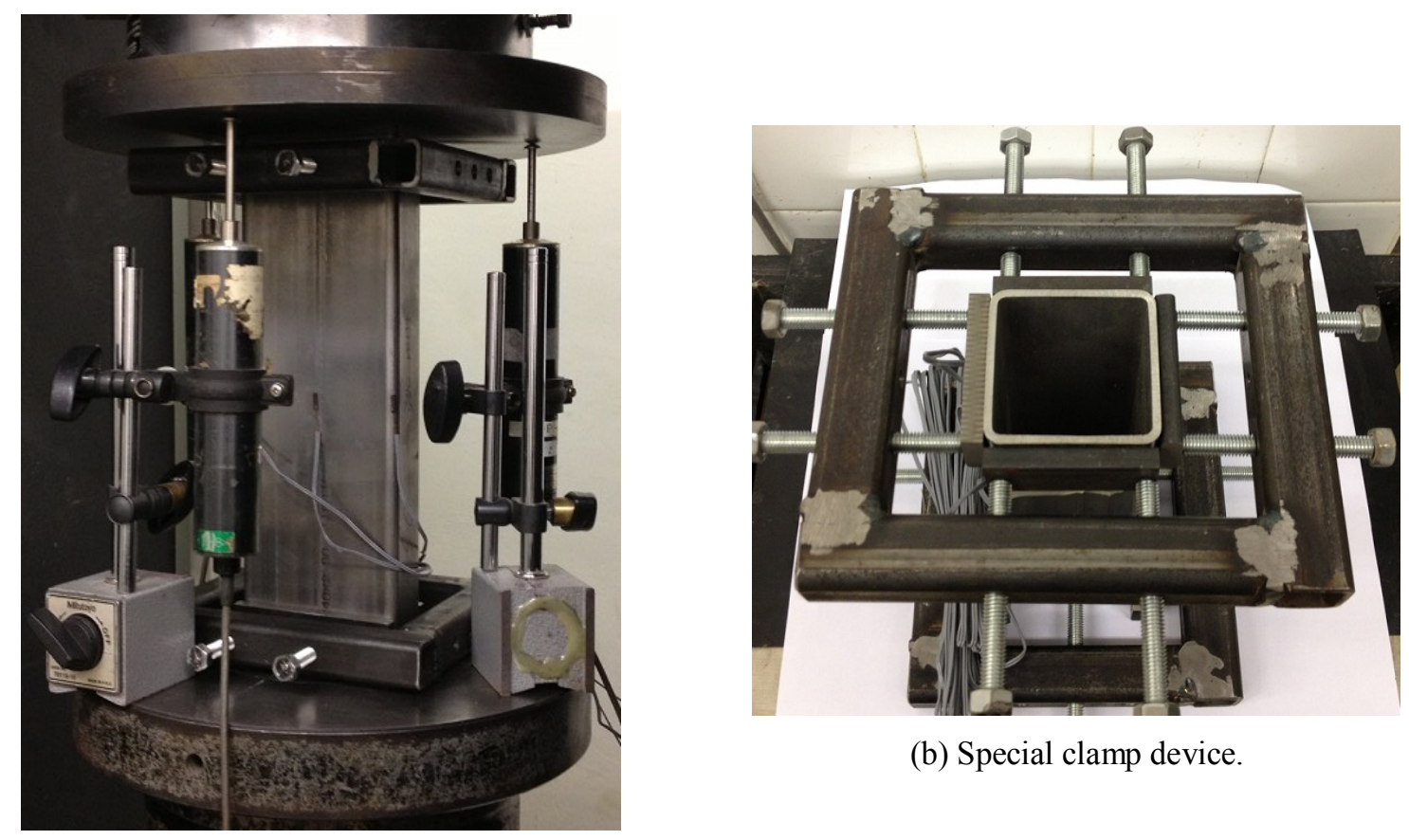

(b) Special clamp device.

(a) Experimental setup.

Fig. 5. Stub column test setup. 


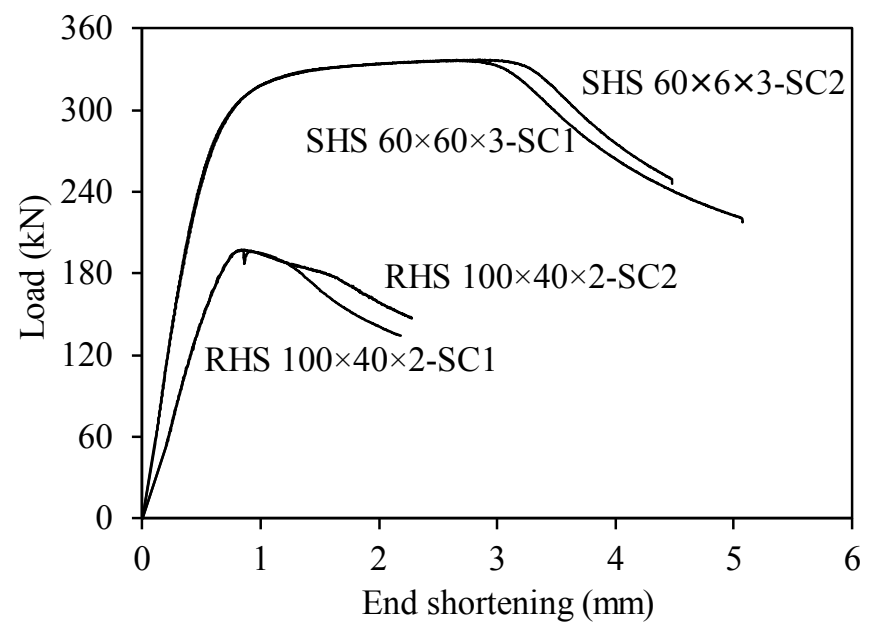

Fig. 6. Load-end shortening curves for stub column tests.

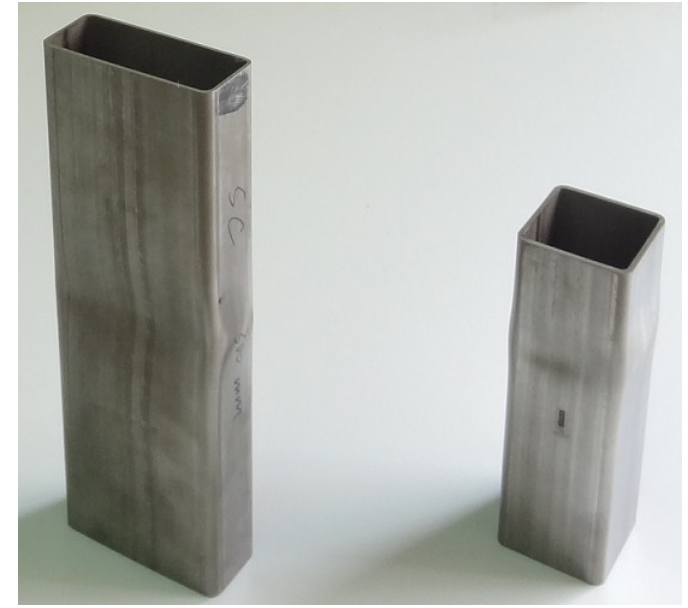

Fig. 7. Stub column failure modes. 


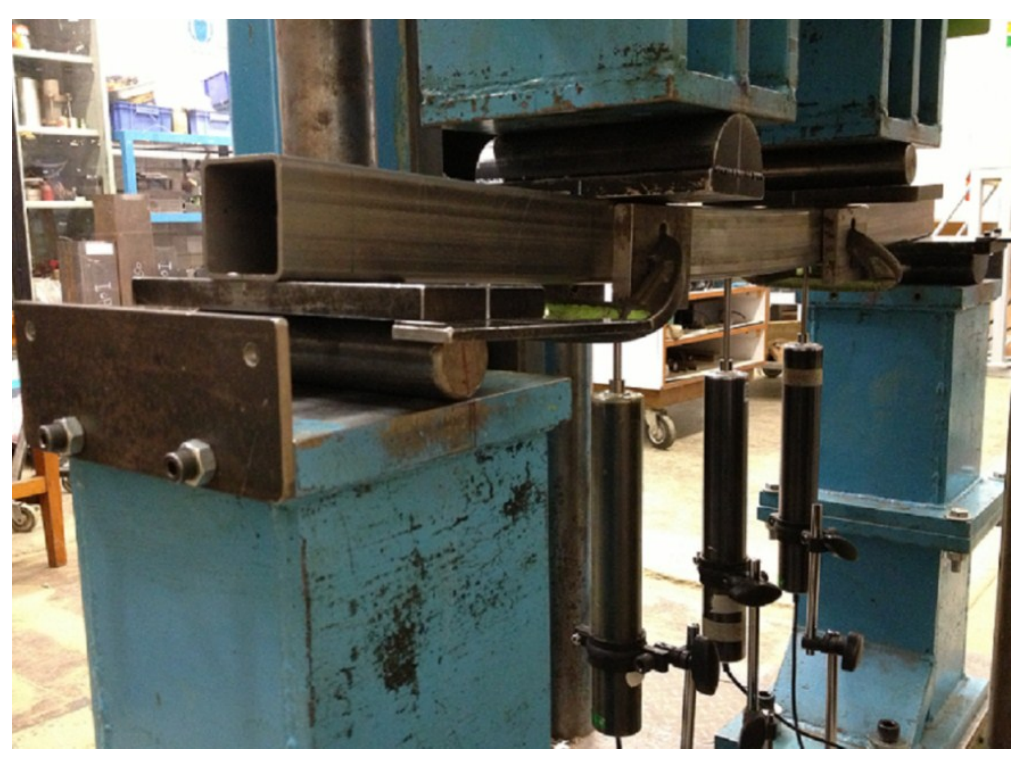

Fig. 8. Four-point bending test setup.

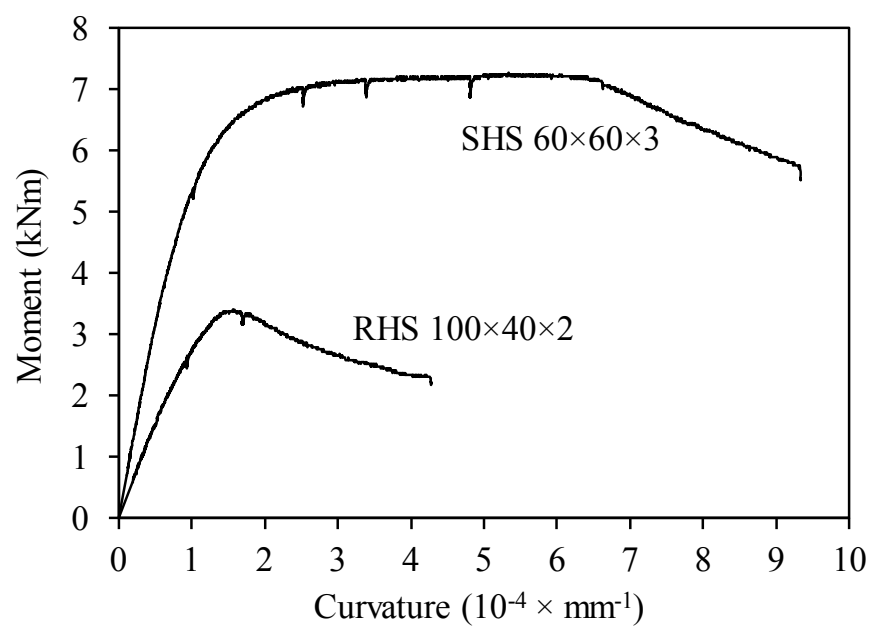

Fig. 9. Moment-curvature curves for four-point bending tests.

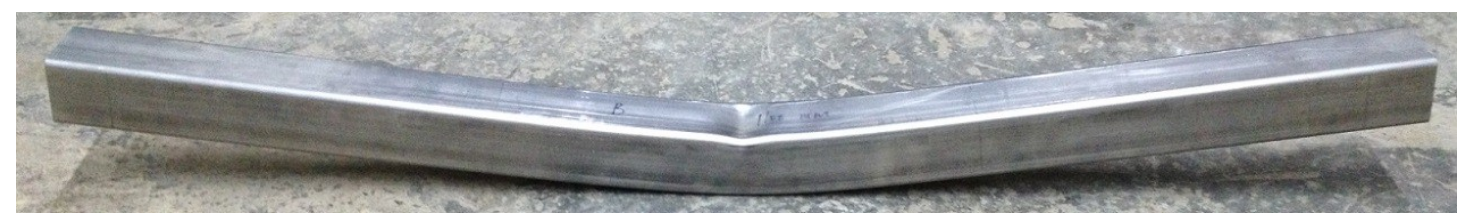

Fig. 10. Experimental and numerical failure modes for beam specimen SHS $60 \times 60 \times 3$. 


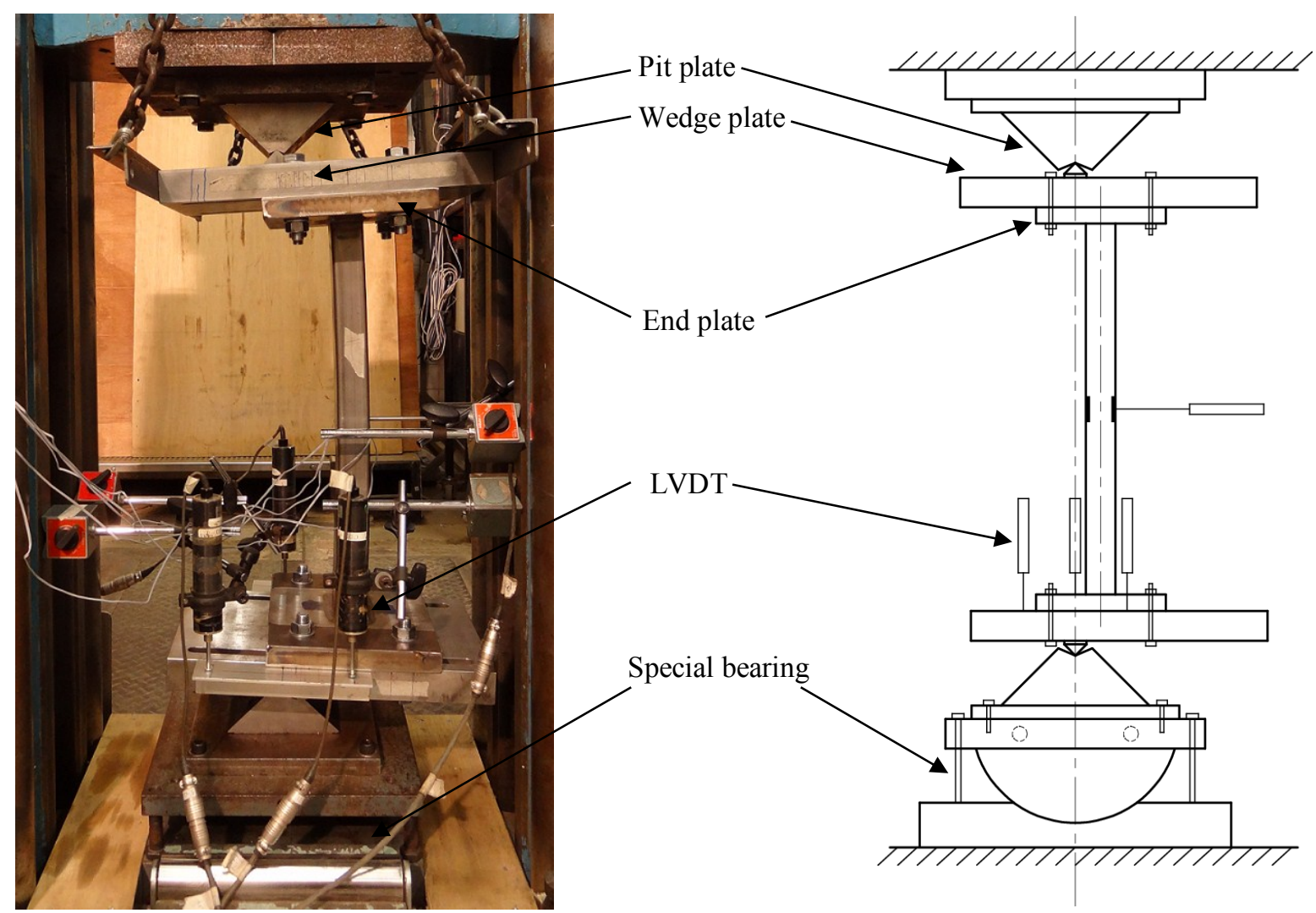

(a) Experimental setup.

(b) Schematic diagram of the test setup.

Fig. 11. Beam-column test configuration.

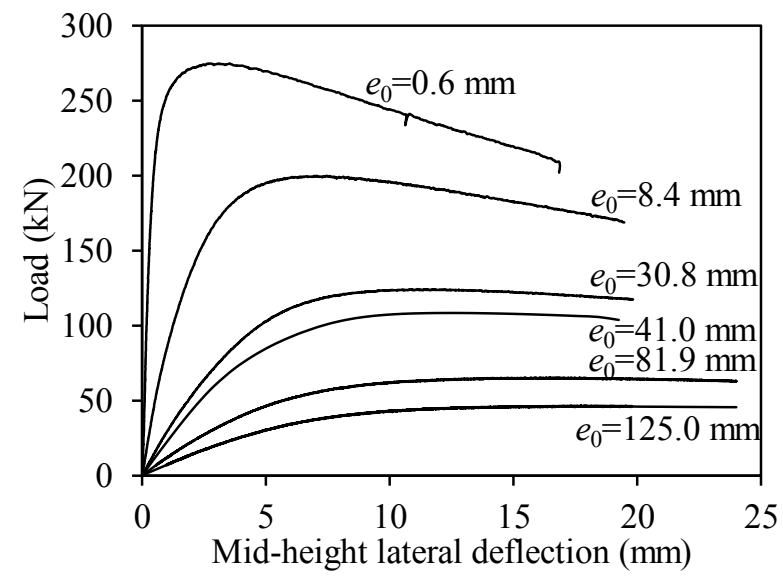

(a) Test curves for SHS $60 \times 60 \times 3$.

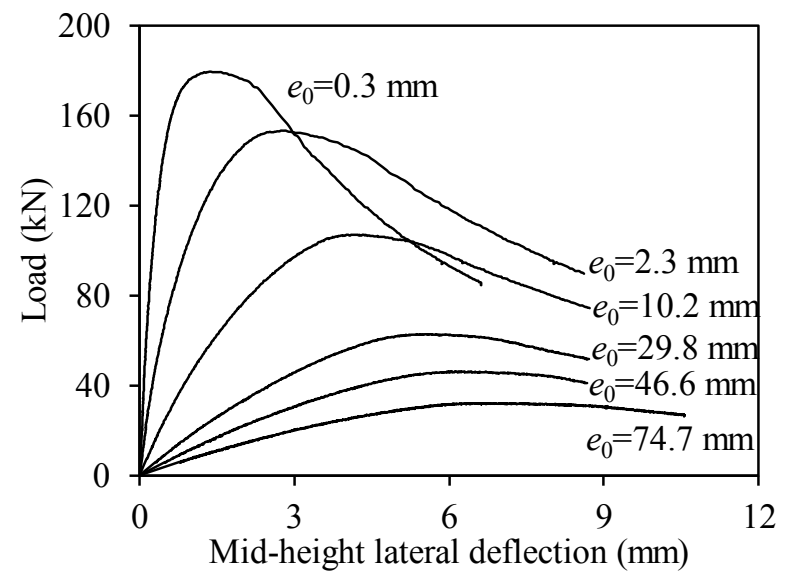

(b) Test curves for RHS $100 \times 40 \times 2$.

Fig. 12. Load-mid-height lateral deflection curves from beam-column tests. 

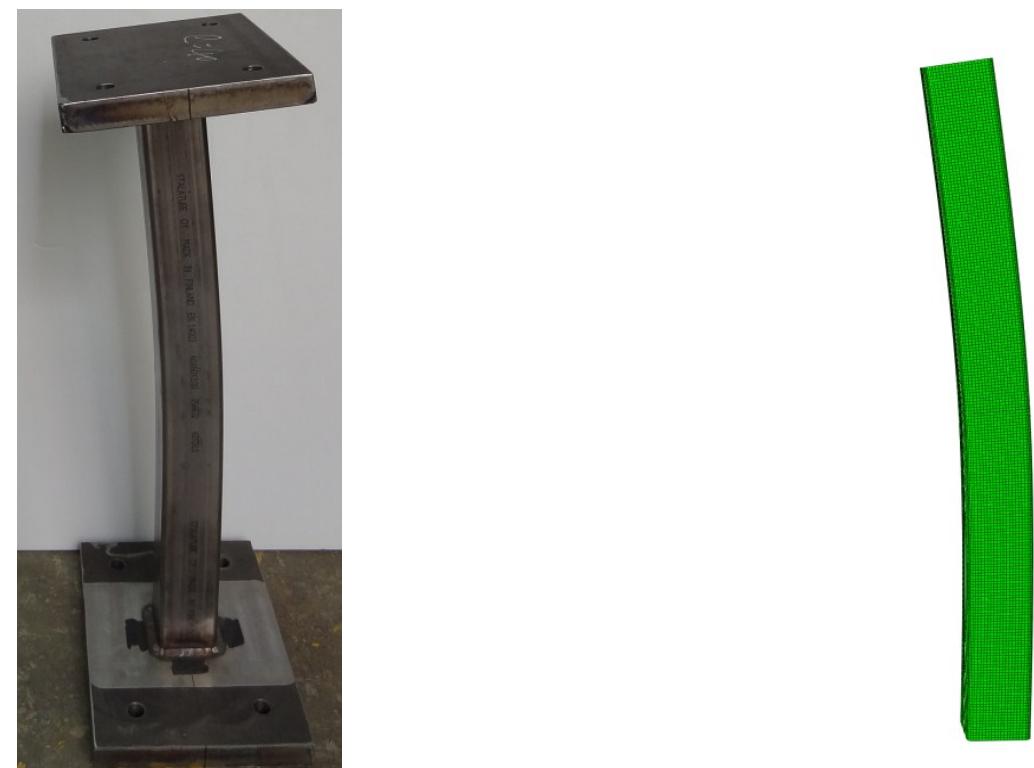

Fig. 13. Experimental and numerical failure modes for specimen SHS $60 \times 60 \times 3-1 B$.
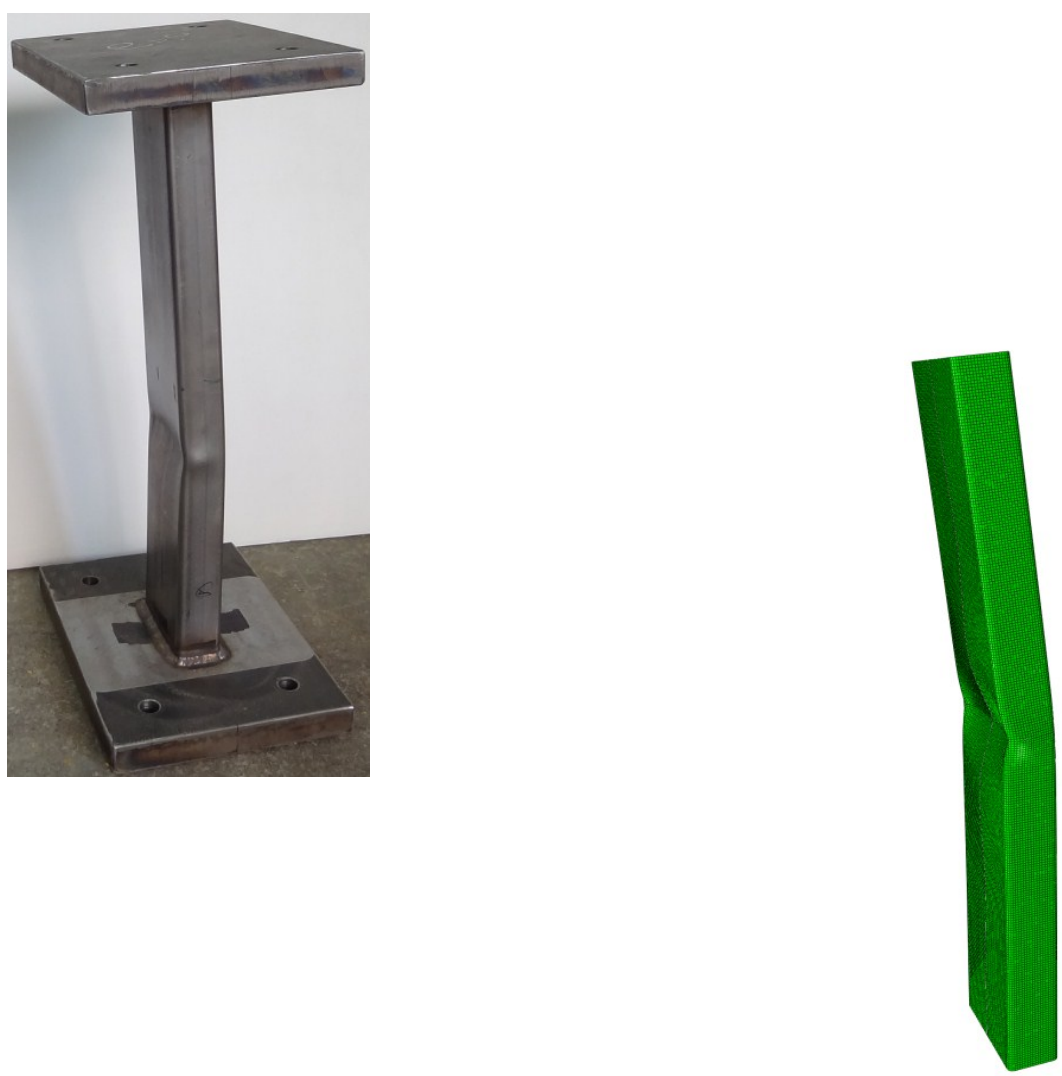

Fig. 14. Experimental and numerical failure modes for specimen RHS $100 \times 40 \times 2-2 \mathrm{C}$. 


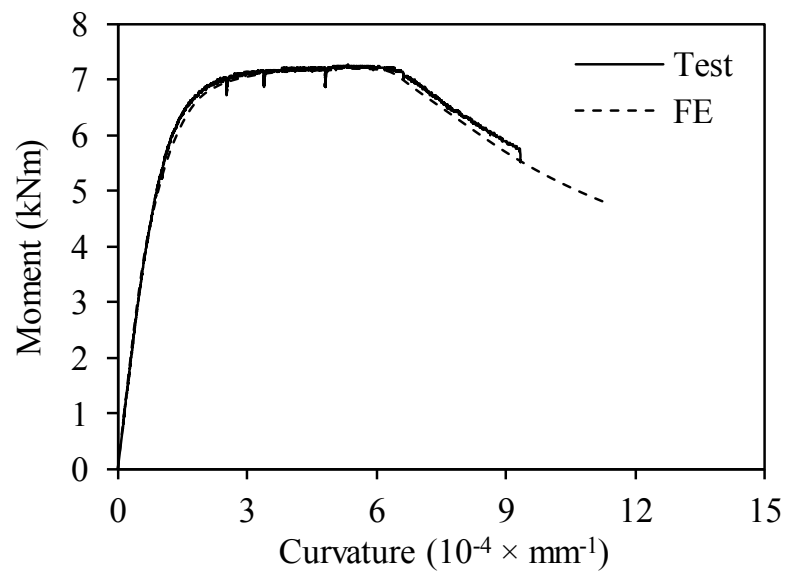

Fig. 15. Experimental and numerical moment-curvature curves for typical beam specimen SHS $60 \times 60 \times 3$.

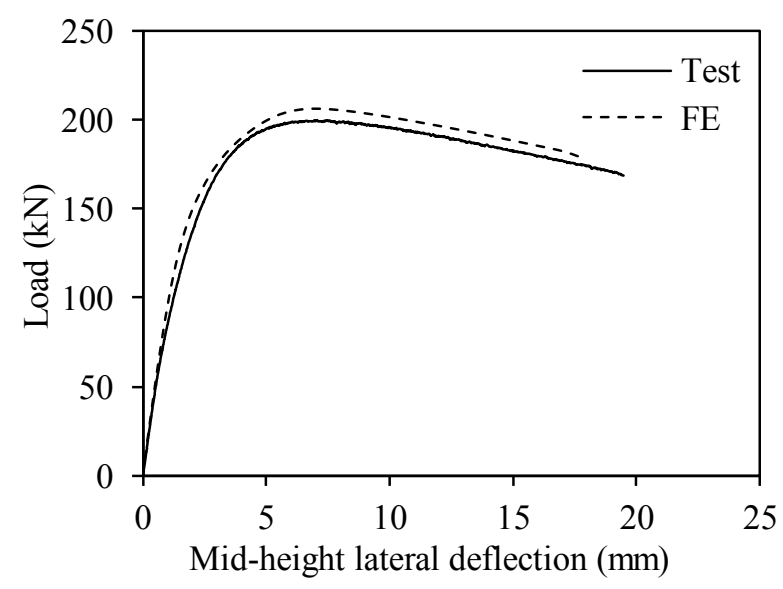

(a) SHS $60 \times 60 \times 3-1 \mathrm{~B}$.

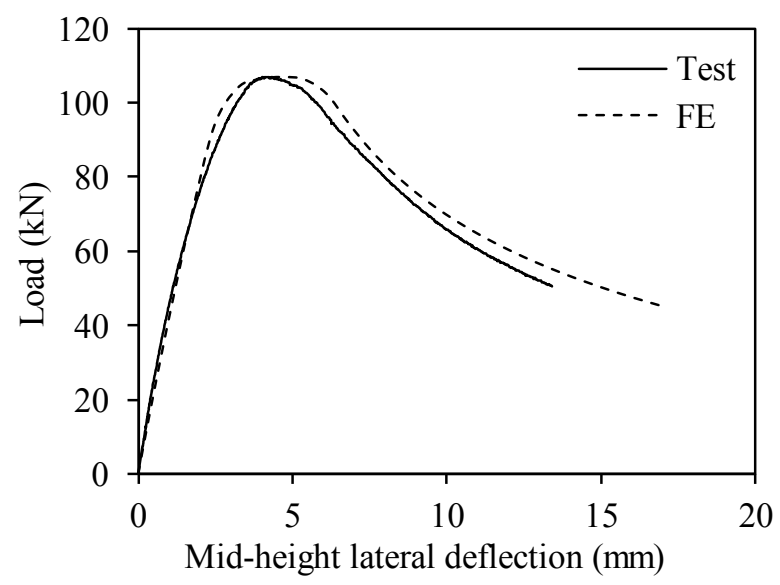

(b) RHS $100 \times 40 \times 2-2 \mathrm{C}$.

Fig. 16. Experimental and numerical load-mid-height lateral deflection curves for typical beam-column specimens. 


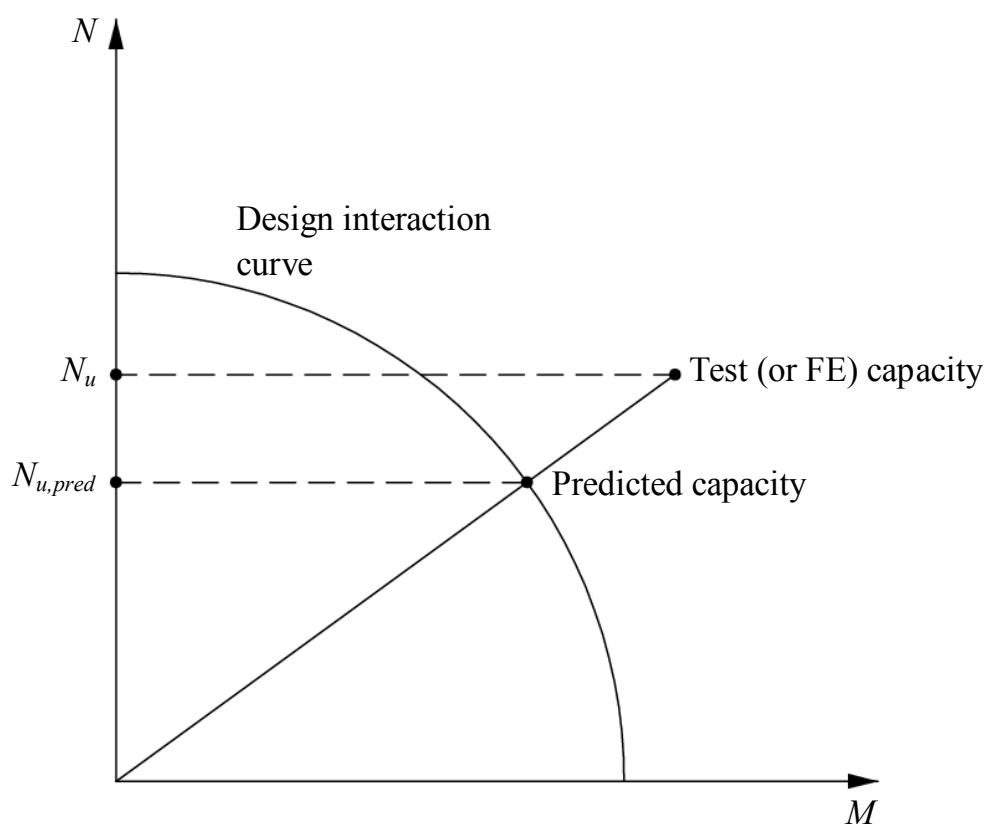

Fig. 17. Definition of $N_{u}$ and $N_{u, p r e d}$ on axial load-moment interaction curve.

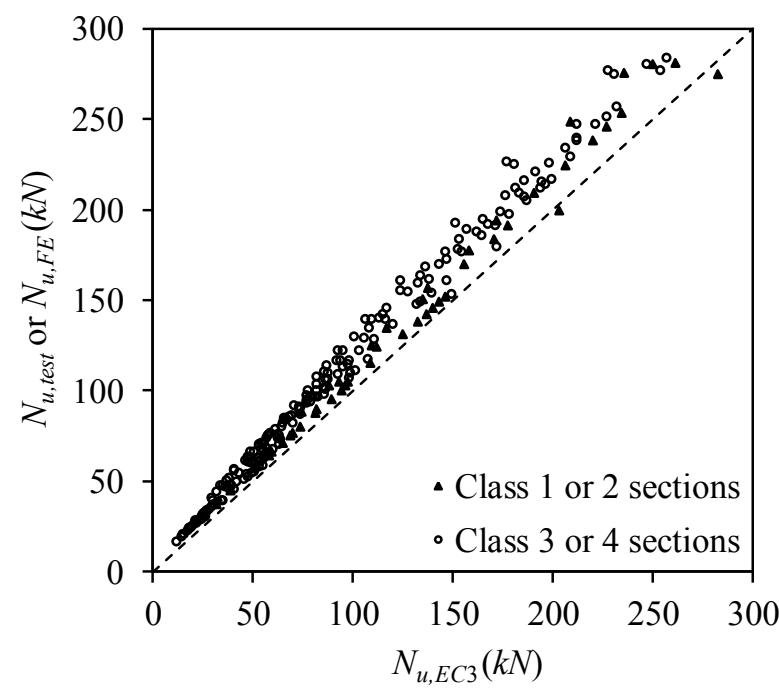

(a) $N_{u, \text { test }}\left(\right.$ or $\left.N_{u, F E}\right)<300 \mathrm{kN}$.

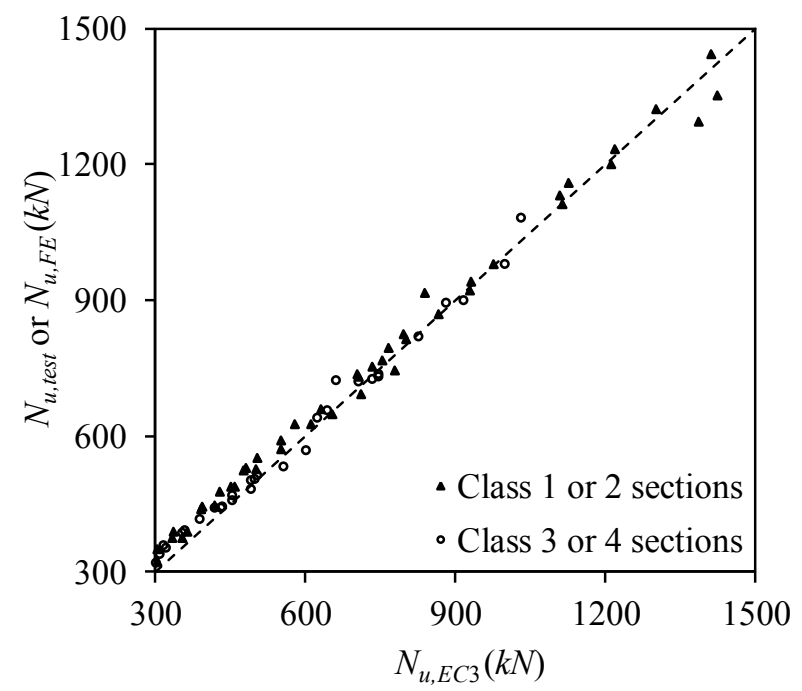

(b) $N_{u, \text { test }}\left(\right.$ or $\left.N_{u, F E}\right)>300 \mathrm{kN}$.

Fig. 18. Comparison of test or FE results with EC3 predictions. 


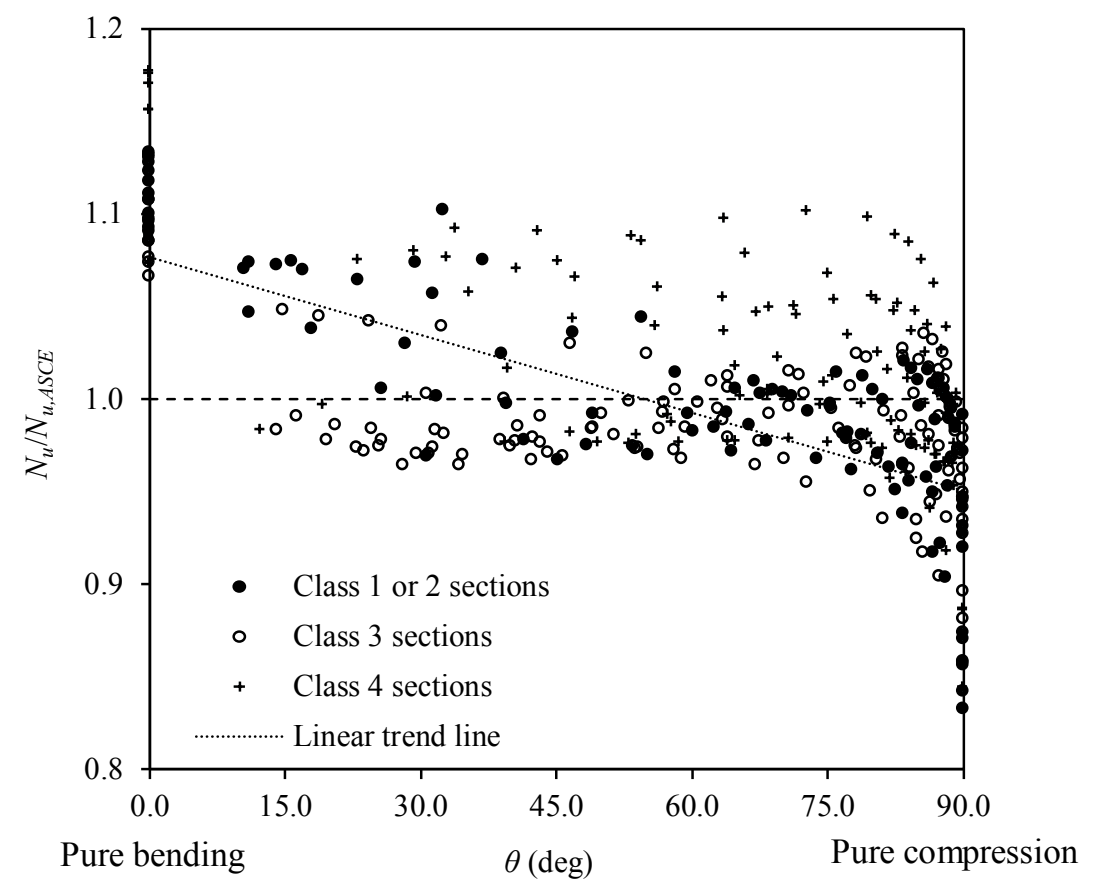

Fig. 19. Comparison of test and FE results with ASCE predictions.

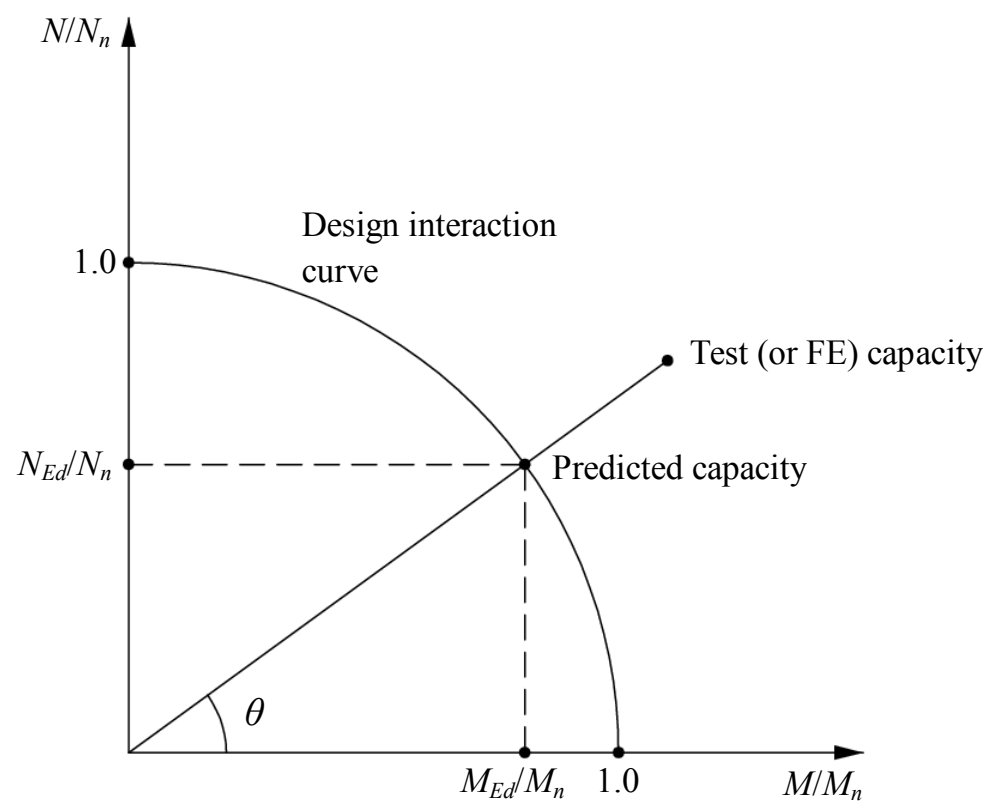

Fig. 20. Definition of $\theta$. 


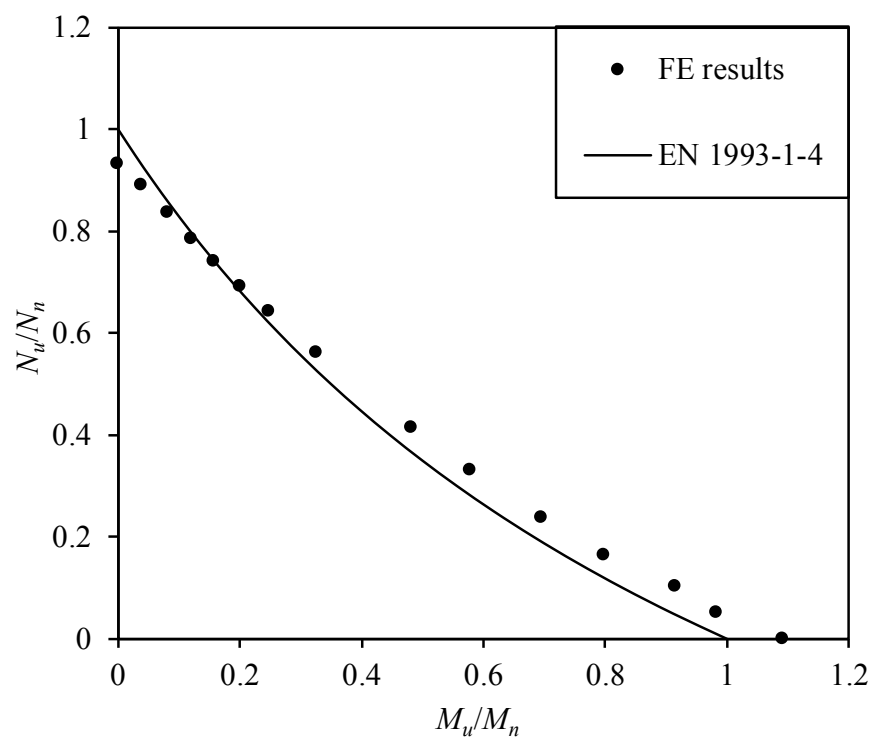

Fig. 21. A typical comparison of FE results of SHS $100 \times 100 \times 10$ beam-columns $(2500 \mathrm{~mm}$ length) with the SEI/ASCE-8 design curve.

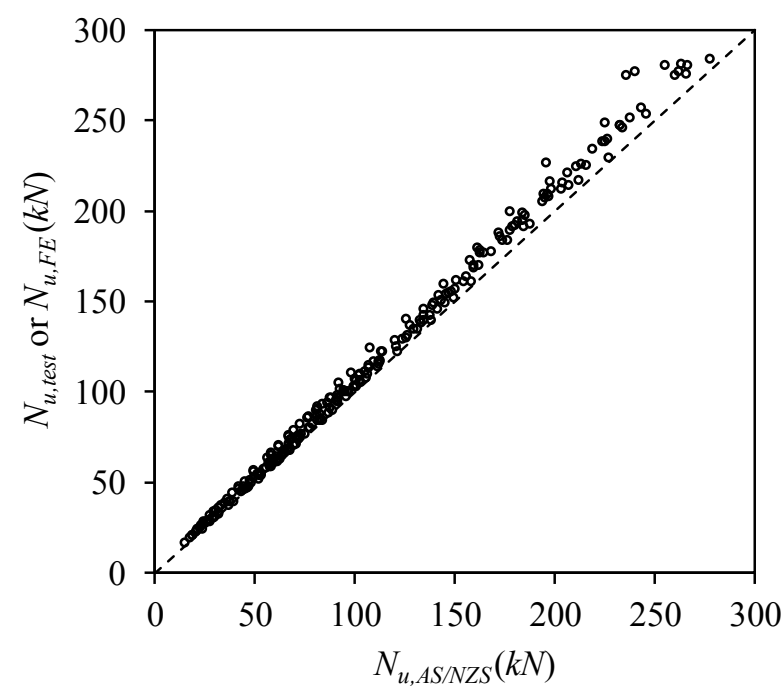

(a) $N_{u, \text { test }}\left(\right.$ or $\left.N_{u, F E}\right)<300 \mathrm{kN}$.

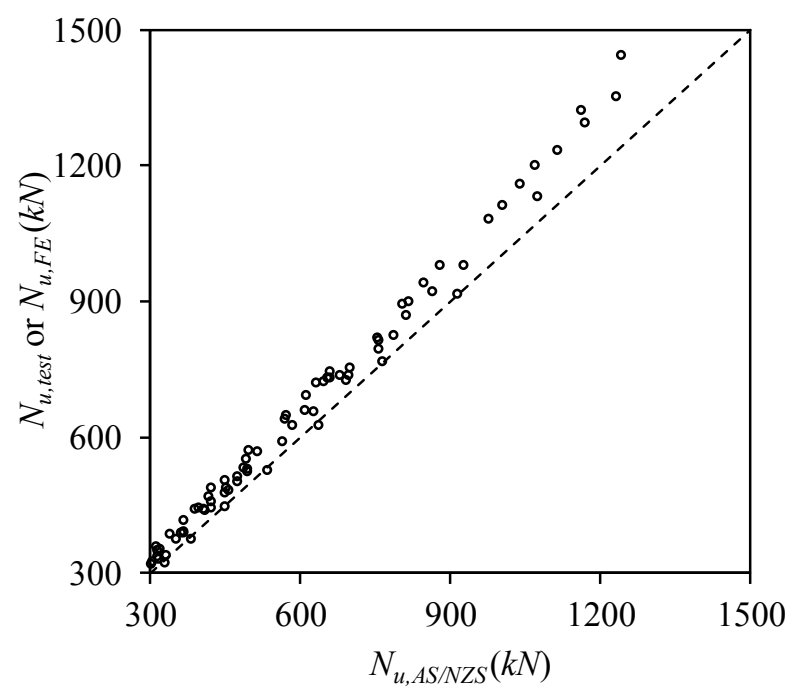

(b) $N_{u, \text { test }}\left(\right.$ or $\left.N_{u, F E}\right)>300 \mathrm{kN}$.

Fig. 22. Comparison of test or FE results with AS/NZS predictions. 


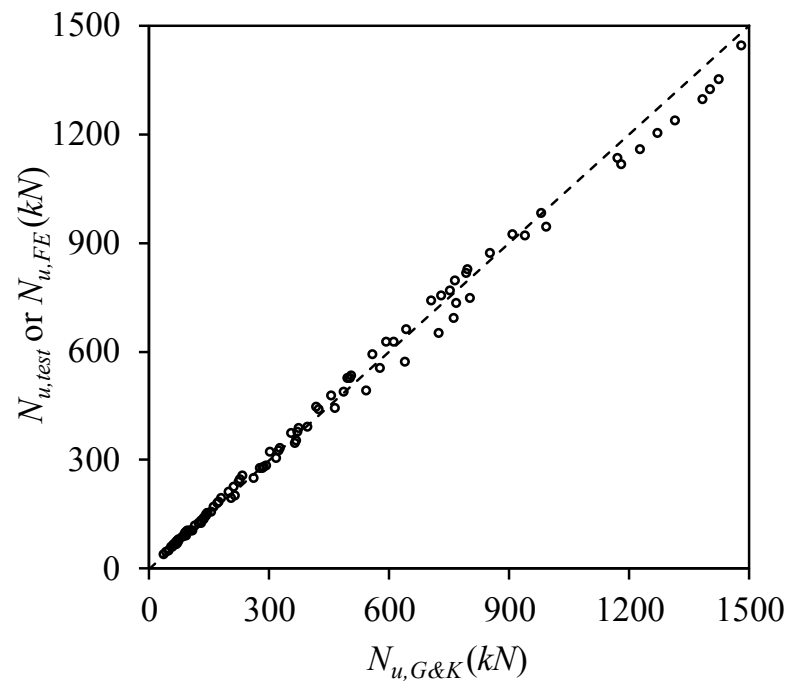

Fig. 23. Comparison of test or FE results with strength predictions of Greiner and Kettler's method (Class 1 and Class 2 cross-sections only).

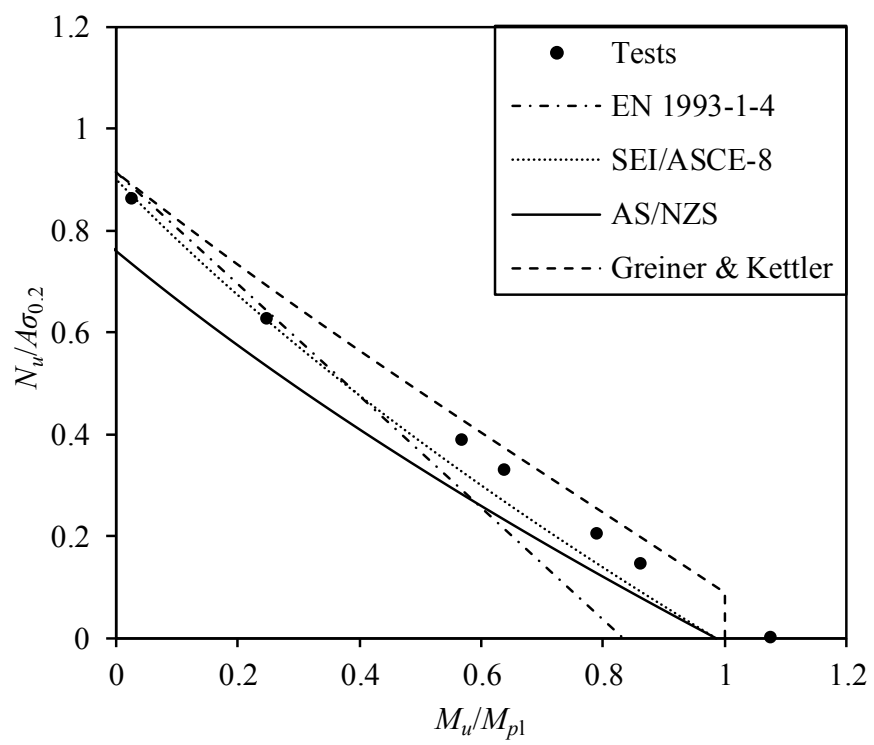

Fig. 24. Comparison of SHS $60 \times 60 \times 3$ beam-column test results with four design interaction curves. 


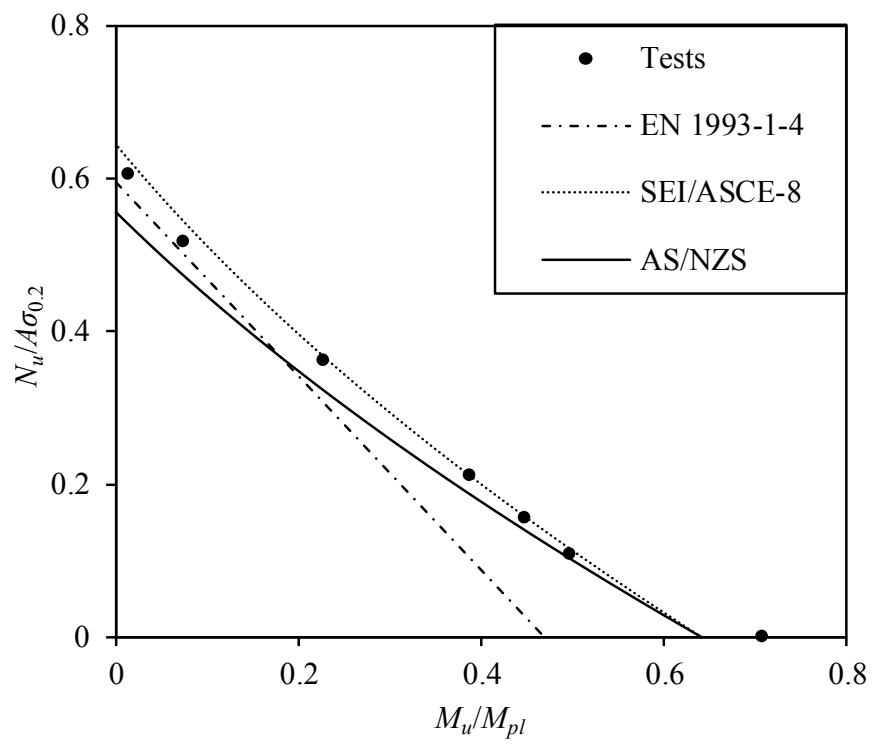

Fig. 25. Comparison of RHS $100 \times 40 \times 2$ beam-column test results with three design interaction curves. Note that comparisons are not made with the Greiner and Kettler curve for the RHS $100 \times 40 \times 2$ beam-columns since the cross-section is not Class 1 or 2 . 
Table 1 Average measured tensile flat material properties.

\begin{tabular}{cccccccccc}
\hline Cross-section & $E$ & $\sigma_{0.2}$ & $\sigma_{1.0}$ & $\sigma_{u}$ & $\varepsilon_{u}$ & $\varepsilon_{f}$ & \multicolumn{2}{c}{ R-O coefficient } \\
\cline { 7 - 10 } & $\left(\mathrm{N} / \mathrm{mm}^{2}\right)$ & $\left(\mathrm{N} / \mathrm{mm}^{2}\right)$ & $\left(\mathrm{N} / \mathrm{mm}^{2}\right)$ & $\left(\mathrm{N} / \mathrm{mm}^{2}\right)$ & $(\%)$ & $(\%)$ & $n$ & $n_{0.2, u}^{\prime}$ & $n_{0.2,1.0}^{\prime}$ \\
\hline SHS $60 \times 60 \times 3$ & 198560 & 470 & 485 & 488 & 7.4 & 21.1 & 7.3 & 7.6 & 10.9 \\
RHS $100 \times 40 \times 2$ & 197400 & 449 & 457 & 483 & 14.5 & 29.2 & 8.8 & 3.4 & 2.3 \\
\hline
\end{tabular}

Table 2 Average measured tensile corner material properties.

\begin{tabular}{|c|c|c|c|c|c|c|c|c|c|}
\hline \multirow[t]{2}{*}{ Cross-section } & \multirow{2}{*}{$\begin{array}{c}E \\
\left(\mathrm{~N} / \mathrm{mm}^{2}\right)\end{array}$} & \multirow{2}{*}{$\begin{array}{c}\sigma_{0.2} \\
\left(\mathrm{~N} / \mathrm{mm}^{2}\right)\end{array}$} & \multirow{2}{*}{$\begin{array}{c}\sigma_{1.0} \\
\left(\mathrm{~N} / \mathrm{mm}^{2}\right)\end{array}$} & \multirow{2}{*}{$\begin{array}{c}\sigma_{u} \\
\left(\mathrm{~N} / \mathrm{mm}^{2}\right)\end{array}$} & \multirow{2}{*}{$\begin{array}{c}\varepsilon_{u} \\
(\%)\end{array}$} & \multirow{2}{*}{$\begin{array}{c}\varepsilon_{f} \\
(\%)\end{array}$} & \multicolumn{3}{|c|}{ R-O coefficient } \\
\hline & & & & & & & $n$ & $n_{0.2, u}^{\prime}$ & $n_{0.2,1.0}^{\prime}$ \\
\hline SHS $60 \times 60 \times 3$ & 200195 & 579 & - & 648 & 1.1 & 13.2 & 4.0 & - & 7.3 \\
\hline RHS $100 \times 40 \times 2$ & 193091 & 601 & - & 638 & 1.2 & 9.6 & 5.5 & - & 17.2 \\
\hline
\end{tabular}

Table 3 Summary of stub column dimensions and test results.

\begin{tabular}{|c|c|c|c|c|c|c|c|c|}
\hline Cross-section & $\begin{array}{c}L \\
(\mathrm{~mm})\end{array}$ & $\begin{array}{c}H \\
(\mathrm{~mm})\end{array}$ & $\begin{array}{c}B \\
(\mathrm{~mm})\end{array}$ & $\begin{array}{c}\mathrm{t} \\
(\mathrm{mm})\end{array}$ & $\begin{array}{c}r_{i} \\
(\mathrm{~mm})\end{array}$ & $\begin{array}{c}\omega_{0} \\
(\mathrm{~mm})\end{array}$ & $\begin{array}{c}N_{u} \\
(\mathrm{kN})\end{array}$ & $\begin{array}{c}\delta_{u} \\
(\mathrm{~mm})\end{array}$ \\
\hline SHS $60 \times 60 \times 3-S C 1$ & 195.0 & 59.5 & 59.9 & 2.85 & 3.40 & 0.024 & 336.4 & 2.72 \\
\hline SHS $60 \times 60 \times 3-S C-2$ & 195.1 & 59.9 & 60.0 & 2.85 & 3.40 & 0.024 & 337.0 & 2.83 \\
\hline RHS $100 \times 40 \times 2-S C 1$ & 295.0 & 40.0 & 100.0 & 1.90 & 3.40 & 0.033 & 197.0 & 0.83 \\
\hline RHS $100 \times 40 \times 2-S C 2$ & 295.2 & 40.1 & 99.9 & 1.90 & 3.40 & 0.033 & 197.3 & 0.83 \\
\hline
\end{tabular}

Table 4 Summary of beam dimensions and test results.

\begin{tabular}{ccccccccc}
\hline Cross-section & Axis of bending & $\begin{array}{c}H \\
(\mathrm{~mm})\end{array}$ & $\begin{array}{c}B \\
(\mathrm{~mm})\end{array}$ & $\begin{array}{c}t \\
(\mathrm{~mm})\end{array}$ & $\begin{array}{c}r_{i} \\
(\mathrm{~mm})\end{array}$ & $\begin{array}{c}\omega_{0} \\
(\mathrm{~mm})\end{array}$ & $\begin{array}{c}M_{u} \\
(\mathrm{kNm})\end{array}$ & $\begin{array}{c}\kappa_{u} \\
\left(\mathrm{~mm}^{-1}\right)\end{array}$ \\
\hline SHS $60 \times 60 \times 3$ & - & 60.1 & 60.0 & 2.85 & 3.40 & 0.024 & 7.24 & $5.34 \times 10^{-4}$ \\
RHS $100 \times 40 \times 2$ & Minor & 40.1 & 100.3 & 1.90 & 3.40 & 0.033 & 3.41 & $1.60 \times 10^{-4}$ \\
\hline
\end{tabular}


Table 5 Measured geometric properties of beam-column specimens.

\begin{tabular}{|c|c|c|c|c|c|c|c|c|c|}
\hline Cross-section & Specimen ID & $\bar{\lambda}$ & $\begin{array}{c}L_{e} \\
(\mathrm{~mm})\end{array}$ & $\begin{array}{c}H \\
(\mathrm{~mm})\end{array}$ & $\begin{array}{c}B \\
(\mathrm{~mm})\end{array}$ & $\begin{array}{c}t \\
(\mathrm{~mm})\end{array}$ & $\begin{array}{c}r_{i} \\
(\mathrm{~mm})\end{array}$ & $\begin{array}{c}\omega_{0} \\
(\mathrm{~mm})\end{array}$ & $\begin{array}{c}\omega_{g} \\
(\mathrm{~mm})\end{array}$ \\
\hline \multirow{6}{*}{ SHS $60 \times 60 \times 3$} & $1 \mathrm{~A}$ & 0.54 & 774.8 & 60.2 & 60.2 & 2.85 & 3.40 & 0.024 & 0.127 \\
\hline & $1 \mathrm{~B}$ & 0.54 & 774.8 & 59.8 & 60.0 & 2.85 & 3.40 & 0.024 & 0.127 \\
\hline & $1 \mathrm{C}$ & 0.54 & 774.8 & 59.8 & 60.1 & 2.83 & 3.40 & 0.024 & 0.127 \\
\hline & $1 \mathrm{D}$ & 0.54 & 774.8 & 60.0 & 60.0 & 2.85 & 3.40 & 0.024 & 0.254 \\
\hline & $1 \mathrm{E}$ & 0.54 & 774.8 & 59.8 & 60.0 & 2.85 & 3.40 & 0.024 & 0.190 \\
\hline & $1 F$ & 0.54 & 774.8 & 60.0 & 60.0 & 2.84 & 3.40 & 0.024 & 0.254 \\
\hline \multirow{6}{*}{$\begin{array}{c}\text { RHS } \\
100 \times 40 \times 2-\mathrm{MI}\end{array}$} & $2 \mathrm{~A}$ & 0.56 & 674.8 & 40.2 & 100.2 & 1.90 & 3.40 & 0.033 & 0.127 \\
\hline & $2 \mathrm{~B}$ & 0.56 & 674.8 & 40.0 & 100.0 & 1.90 & 3.40 & 0.033 & 0.254 \\
\hline & $2 \mathrm{C}$ & 0.56 & 674.8 & 39.8 & 100.1 & 1.91 & 3.40 & 0.033 & 0.127 \\
\hline & $2 \mathrm{D}$ & 0.56 & 674.8 & 39.8 & 100.0 & 1.90 & 3.40 & 0.033 & 0.254 \\
\hline & $2 \mathrm{E}$ & 0.56 & 674.8 & 40.1 & 100.3 & 1.89 & 3.40 & 0.033 & 0.381 \\
\hline & $2 \mathrm{~F}$ & 0.56 & 674.8 & 40.0 & 100.0 & 1.90 & 3.40 & 0.033 & 0.190 \\
\hline
\end{tabular}

Note: MI indicates beam-column tests, in which bending was induced about the minor axis.

Table 6 Summary of beam-column test results.

\begin{tabular}{|c|c|c|c|c|c|c|c|c|c|}
\hline Cross-section & Specimen ID & $\begin{array}{c}e_{m} \\
(\mathrm{~mm})\end{array}$ & $\begin{array}{c}e_{0} \\
(\mathrm{~mm})\end{array}$ & $\begin{array}{c}N_{u} \\
(\mathrm{kN})\end{array}$ & $\begin{array}{c}\delta_{u} \\
(\mathrm{~mm})\end{array}$ & $\begin{array}{c}\phi_{u} \\
(\mathrm{deg})\end{array}$ & $\begin{array}{l}M_{1 s t, e l, u} \\
(\mathrm{kNm})\end{array}$ & $\begin{array}{c}M_{2 n d, e l, u} \\
(\mathrm{kNm})\end{array}$ & $\begin{array}{c}M_{2 n d, \text { inel, }} \\
(\mathrm{kNm})\end{array}$ \\
\hline \multirow{6}{*}{ SHS $60 \times 60 \times 3$} & $1 \mathrm{~A}$ & 0.0 & 0.6 & 274.5 & 3.56 & 0.75 & 0.16 & 0.22 & 1.18 \\
\hline & $1 \mathrm{~B}$ & 10.0 & 8.4 & 199.6 & 7.22 & 1.58 & 1.68 & 2.05 & 3.14 \\
\hline & $1 \mathrm{C}$ & 30.0 & 30.8 & 124.1 & 11.17 & 2.62 & 3.82 & 4.31 & 5.22 \\
\hline & 1D & 40.0 & 41.0 & 104.7 & 12.00 & 2.85 & 4.29 & 4.75 & 5.58 \\
\hline & $1 \mathrm{E}$ & 80.0 & 81.9 & 65.0 & 16.44 & 3.88 & 5.32 & 5.66 & 6.40 \\
\hline & $1 \mathrm{~F}$ & 125.0 & 125.0 & 46.4 & 18.28 & 4.58 & 5.80 & 6.06 & 6.66 \\
\hline \multirow{6}{*}{$\begin{array}{c}\text { RHS } \\
100 \times 40 \times 2-M I\end{array}$} & $2 \mathrm{~A}$ & 0.0 & 0.3 & 179.4 & 1.37 & 0.35 & 0.05 & 0.08 & 0.32 \\
\hline & $2 \mathrm{~B}$ & 2.0 & 2.3 & 153.2 & 2.74 & 0.69 & 0.35 & 0.47 & 0.81 \\
\hline & $2 \mathrm{C}$ & 10.0 & 10.2 & 106.9 & 4.17 & 1.15 & 1.09 & 1.32 & 1.55 \\
\hline & $2 \mathrm{D}$ & 30.0 & 29.8 & 62.7 & 5.93 & 1.72 & 1.87 & 2.08 & 2.26 \\
\hline & $2 \mathrm{E}$ & 45.0 & 46.6 & 46.3 & 6.08 & 1.73 & 2.16 & 2.33 & 2.46 \\
\hline & $2 \mathrm{~F}$ & 75.0 & 74.7 & 32.0 & 7.41 & 2.22 & 2.39 & 2.52 & 2.63 \\
\hline
\end{tabular}

Table 7 The adopted local imperfection amplitudes in beam models.

\begin{tabular}{cccc}
\hline Cross-section & $\omega_{0}$ & $t / 100$ & $\omega_{D \& W}$ \\
\hline SHS $60 \times 60 \times 3$ & 0.024 & 0.029 & 0.013 \\
RHS $100 \times 40 \times 2$ & 0.033 & 0.019 & 0.064 \\
\hline
\end{tabular}


Table 8 Comparison of beam-column test results with FE results for varying imperfection amplitudes.

\begin{tabular}{|c|c|c|c|c|c|c|c|}
\hline \multirow{2}{*}{ Cross-section } & \multirow{2}{*}{$\begin{array}{l}\text { Specimen } \\
\text { ID }\end{array}$} & \multicolumn{6}{|c|}{ FE $N_{u} /$ Test $N_{u}$} \\
\hline & & $\omega_{g}+\omega_{0}$ & $L / 1000+\omega_{0}$ & $L / 1500+\omega_{0}$ & $\omega_{g}+\omega_{D \& W}$ & $L / 1000+\omega_{D \& W}$ & $L / 1500+\omega_{D \& W}$ \\
\hline \multirow{6}{*}{ SHS $60 \times 60 \times 3$} & $1 \mathrm{~A}$ & 1.013 & 0.981 & 0.993 & 1.013 & 0.981 & 0.993 \\
\hline & $1 \mathrm{~B}$ & 1.032 & 1.019 & 1.026 & 1.033 & 1.019 & 1.026 \\
\hline & $1 \mathrm{C}$ & 1.024 & 1.014 & 1.018 & 1.025 & 1.015 & 1.019 \\
\hline & $1 \mathrm{D}$ & 1.034 & 1.025 & 1.028 & 1.034 & 1.025 & 1.029 \\
\hline & $1 \mathrm{E}$ & 1.042 & 1.037 & 1.039 & 1.043 & 1.037 & 1.039 \\
\hline & $1 \mathrm{~F}$ & 1.043 & 1.040 & 1.041 & 1.043 & 1.040 & 1.042 \\
\hline \multirow{6}{*}{$\begin{array}{c}\text { RHS } \\
100 \times 40 \times 2-M I\end{array}$} & $2 \mathrm{~A}$ & 0.973 & 0.942 & 0.954 & 0.967 & 0.937 & 0.948 \\
\hline & $2 \mathrm{~B}$ & 1.001 & 0.976 & 0.986 & 0.995 & 0.972 & 0.981 \\
\hline & $2 \mathrm{C}$ & 1.000 & 0.989 & 0.995 & 0.997 & 0.984 & 0.990 \\
\hline & $2 \mathrm{D}$ & 1.022 & 1.014 & 1.018 & 1.019 & 1.012 & 1.015 \\
\hline & $2 \mathrm{E}$ & 1.039 & 1.034 & 1.036 & 1.037 & 1.032 & 1.034 \\
\hline & $2 \mathrm{~F}$ & 1.068 & 1.065 & 1.066 & 1.066 & 1.063 & 1.064 \\
\hline Mean & & 1.024 & 1.011 & 1.017 & 1.023 & 1.010 & 1.015 \\
\hline $\mathrm{COV}$ & & 0.024 & 0.033 & 0.030 & 0.026 & 0.035 & 0.031 \\
\hline
\end{tabular}

Table 9 Comparison of the four-point bending test results with FE results for varying imperfection amplitudes.

\begin{tabular}{cccc}
\hline Specimen & \multicolumn{3}{c}{ FE $M_{u} /$ Test $M_{u}$} \\
\cline { 2 - 4 } & $\omega_{0}$ & $t / 100$ & $\omega_{D \& W}$ \\
\hline SHS $60 \times 60 \times 3$ & 0.994 & 0.989 & 1.000 \\
RHS $100 \times 40 \times 2$ & 0.975 & 0.980 & 0.970 \\
\hline Mean & 0.984 & 0.985 & 0.985 \\
COV & 0.014 & 0.006 & 0.022 \\
\hline
\end{tabular}


Table 10 Comparison of beam-column test and FE results with predicted strengths for Class 1 or 2 crosssections.

\begin{tabular}{ccccc}
\hline $\begin{array}{c}\text { No. of tests: } 7 \\
\text { No. of FE simulations: } 110\end{array}$ & $N_{u} / N_{u, E C 3}$ & $N_{u} / N_{u, A S C E}$ & $N_{u} / N_{u, A S / N Z S}$ & $N_{u} / N_{u, G \& K}$ \\
\hline Mean & 1.07 & 0.98 & 1.06 & 1.00 \\
COV & 0.06 & 0.06 & 0.04 & 0.06 \\
\hline
\end{tabular}

Table 11 Comparison of beam-column test and FE results with predicted strengths for Class 3 cross-sections.

\begin{tabular}{cccc}
\hline $\begin{array}{c}\text { No. of tests: } 0 \\
\text { No. of FE simulations: } 120\end{array}$ & $N_{u} / N_{u, E C 3}$ & $N_{u} / N_{u, A S C E}$ & $N_{u} / N_{u, A S / N Z S}$ \\
\hline Mean & 1.17 & 0.98 & 1.05 \\
COV & 0.09 & 0.03 & 0.03 \\
\hline
\end{tabular}

Table 12 Comparison of beam-column test and FE results with predicted strengths for Class 4 cross-sections.

\begin{tabular}{cccc}
\hline $\begin{array}{c}\text { No. of tests: } 7 \\
\text { No. of FE simulations: } 110\end{array}$ & $N_{u} / N_{u, E C 3}$ & $N_{u} / N_{u, A S C E}$ & $N_{u} / N_{u, A S / N Z S}$ \\
\hline Mean & 1.20 & 1.02 & 1.09 \\
COV & 0.08 & 0.06 & 0.04 \\
\hline
\end{tabular}

